Applied Mechanics and Materials 


\section{Applied Mechanics and Materials Vol. 815}

https://doi.org/10.4028/www.scientific.net/AMM.815

Preface, Committees \& Conference Organization

Effect of Incubation Temperature on Growth of Acetobacter

xylinum 0416 and Bacterial Cellulose Production

Authors: Khairul Azly Zahan, Khairunnisa Nordin, Mahfuzah Mustapha, Mohd

Naqiuddin Mohd Zairi

Abstract: The objective of this research was to investigate the effect of incubation temperature towards the growth of Acetobacter xylinum 0416 and the production of bacterial cellulose. Fermentation of A.xylinum 0416 were carried out for 5 days in static condition using Hestrin \& Schramm (HS) medium with initial glucose concentration of $4.0 \%(\mathrm{w} / \mathrm{v})$ and initial $\mathrm{pH}$ of 6.4 . The incubation temperature were varied at $5^{\circ} \mathrm{C}, 20^{\circ} \mathrm{C}$, $25^{\circ} \mathrm{C}, 27^{\circ} \mathrm{C}, 28^{\circ} \mathrm{C}, 30^{\circ} \mathrm{C}, 35^{\circ} \mathrm{C}$ and $40^{\circ} \mathrm{C}$ respectively. Results indicated that $28^{\circ} \mathrm{C}$ served as the best incubation temperature for the growth of A.xylinum 0416 and produced the highest amount of bacterial cellulose with total dried weight of $0.3722 \mathrm{~g} / \mathrm{l}$. Meanwhile at incubation temperature of $5^{\circ} \mathrm{C}$ and $40^{\circ} \mathrm{C}$, no significant growth of A.xylinum 0416 and bacterial cellulose were obtained. As a conclusion, incubation temperature plays an important role for the growth of A.xylinum 0416. The best incubation temperature is at $28^{\circ} \mathrm{C}$ in which the sufficient energy will be provided for bacterial growth thus enhancing the cellulose biosynthetic pathway in order to convert glucose into bacterial cellulose.

...more

Thermal Properties of Low Density Polyethylene/Jackfruit Seed Flour Blends-Effect of Hexanedioic Acid Authors: P. Santhiya, S.T. Sam, H. Kamarudin, S. Ragunathan, N.Z. Noriman, A.M.M. Al-Bakri

Abstract: The effects of adding hexanedioic acid (HA) into low density polyethylene (LDPE)/jackfruit seeds (JSF) blends on the properties were investigated by using differential scanning calorimetry (DSC). The influence of the crystallinity and thermal properties of HA on LDPE at various compositions was investigated. JSF was blended with LDPE by using internal mixer (Brabender) at temperature $150^{\circ} \mathrm{C}$. JSF content was varied from 0 to $20 \mathrm{wt} \%$. Crystallinity of the blends was significantly reduced with increasing JSF content and further increased with the presence of HA. Therefore, the crystallinity of the blends was improved with the presence of HA. ...more

Crystallinity and Influence of Citric Acid as a Compatibilizer in Low Density Polyethylene/Jackfruit Seed Flour Blends Authors: P. Santhiya, S.T. Sam, H. Kamarudin, S. Ragunathan, N.Z. Noriman, A.M.M. Al-Bakri 
Abstract: The properties of blends made from low density polyethylene (LDPE) with various concentration of jackfruit seeds flour (JSF) with the presence of citric acid (CA) were investigated. The JSF content was varied from 0 to $20 \mathrm{wt} \%$. The JSF were blended with LDPE by using an internal mixer (Brabender) at a temperature of $150^{\circ} \mathrm{C}$. The test was carried out by using differential scanning calorimetry (DSC), with heating temperature of $100 \mathrm{C} / \mathrm{min}$. The crystallinity had improved with the presence of CA. However, the crystallinity slightly reduced with the increasing JSF content and further increased with the presence of CA.

...more

Properties of Ethylene Propylene Diene Monomer/Recycled Acrylonitrile - Butadiene Rubber Blends (EPDM/rNBR): Effect of the Addition of Bamboo Fillers Authors: Z. Norhafizah, N.Z. Noriman, H. Kamarudin, S.T. Sam, Hanafi Ismail, Mohd Firdaus Omar, Che Mohd Ruzaidi, A.A. Afiratul Abstract: Cure characteristics and physical properties of EPDM/rNBR filled bamboo fillers were studied. Results indicated that the addition of bamboo fillers has significant effects on EPDM/rNBR blends. The scorch time, $\mathrm{t}_{2}$ decreased up to $25 \mathrm{phr}$ fillers loading but increased further to $50 \mathrm{phr}$ fillers loading. Cure time, to increases as the increase in bamboo fillers in the blends. At a similar blend ratio fine sizes bamboo fillers in EPDM/rNBR (S1: $\leq 125 \mu \mathrm{m})$ exhibited higher value of $\mathrm{t}_{2}$ ad $\mathrm{t}_{90}$ compared to EPDM/rNBR (S2: $125-250 \mu \mathrm{m} \&$ S3: $250-500 \mu \mathrm{m}$ ). The minimum torque, $\mathrm{M}_{\mathrm{L}}$ also increases with increasing bamboo fillers in the blend. Meanwhile, the maximum torque, $M_{H}$ of the EPDM/rNBR filled bamboo fillers were in contrast. The hardness and degree of crosslink density of the blends increased with the increase in bamboo fillers and reduce percentage of resilience at all blends. The fine sizes of bamboo fillers contributed to the better properties compared to the coarse sizes and medium sizes. ...more

The Effects on the Cure Characteristics and Physical Properties of Bamboo Activated Carbon Filled Styrene Butadiene Rubber (SBR) Compounds Authors: N.R. Munirah, N.Z. Noriman, M.Z. Salihin, H. Kamarudin, M.H. Fatin, S.T. Sam, A.M. Mustafa Al Bakri

Abstract: The role of activated carbon (AC) in rubber compounds was investigated to better understand the reinforcing mechanism. The activated carbon filled styrene butadiene rubber vulcanizates (SBR-AC) using bamboo activated carbon as filler were prepared by using two-roll mill and cured at $160^{\circ} \mathrm{C}$. AC filler loading from 10 to $50 \mathrm{phr}$ (part per hundred rubber) were used in this study. Study into the influences of filler loading on the cure characteristics, swelling behaviour and physical properties (hardness and resilience) of SBR-AC vulcanizates were carried out. It was observed that SBR-AC vulcanizates has better cure characteristics compared to the styrene butadiene rubber gum vulcanizate (SBR-GV) which is a non-filled vulcanizate. The 
results showed that the scorch time $\left(\mathrm{t}_{\mathrm{s} 2}\right)$ decreased with increasing filler loading. The cure time ( $\mathrm{t}_{c_{0}}$ ) slightly decreased up to $20 \mathrm{phr}$ before a rise as the filler loading increased. The minimum torque $\left(\mathrm{M}_{\mathrm{L}}\right)$ of SBR vulcanizate increased and the maximum torque $\left(\mathrm{M}_{\mathrm{H}}\right)$ decreased up to $20 \mathrm{phr}$ but then increased with increasing filler loading. The cure rate index (CRI) of SBR-GV vulcanizate was higher than that of all SBR-AC vulcanizates. Up to $20 \mathrm{phr}$ of filler loading, the $\mathrm{CRI}$ increased before a decline occurred as the filler loading increased. As expected, the hardness value of SBR-AC vulcanizates was higher compared to SBR-GV vulcanizate which has lower resilience. The hardness and crosslink density showed an increasing trend meanwhile the resilience was adversely affected by the increase in filler loading. Bamboo activated carbon showed some potential enhancement on the reinforcing and physical properties of the vulcanizates.

...more

Performance of Concrete by Using Palm Oil Fuel Ash (POFA) as a Cement Replacement Material Authors: Liyana Ahmad Sofri, Mohd Zulham Affandi Mohd Zahid, Nur Fitriah Isa, Muhammad Azizi Azizan, Muhammad Munsif Ahmad, Mohd Badrul Hisyam Ab Manaf, Mustaqqim Abdul Rahim, Zuhayr Md Ghazaly, Juraida Abu Bakar, Muhammad Shafiq Aiman Ahmran

Abstract: Palm Oil Fuel Ash (POFA) is one of the solid waste in Malaysia and had trouble with the ash removal. Therefore, the use of waste oil palm ash can overcome the problem of solid waste. POFA is a pozzolanic material and it can act as a replacement of cement (OPC) to produce concrete with higher strength and low cost. POFA quality will increase as the range made up to a medium level of fineness in the size of 50 microns. POFA used to replace OPC is $0 \%, 10 \%, 30 \%$ and $50 \%$ by weight percent of OPC. POFA concrete compressive strength will be tested after a curing process that concrete age of 7 days and 28 days. POFA concrete density is also tested and compared with OPC concrete. Results showed that compressive strength POFA lower than normal concrete. On the other hand, the replacement of cement by $10 \%$ POFA shows a record high in compressive strength compared with other POFA mixing at the age of 7 days and 28 days. Fineness pozzolanic POFA is the best material and can be used as a cement replacement alternative.

...more

Mechanical and Thermal Properties of Polylactic Acid Filled Rice Straw Authors: Nurul Hani Md Zubir, S.T. Sam, H. Kamarudin, S. Ragunathan, N.Z. Noriman, Mohd Mustafa Al Bakri Abdullah, Wang Jing

Abstract: Natural fiber reinforced polylactic acid based biocomposites are broadly considered by the researchers to compete with non-renewable petroleum based products. In this study, the biodegradable composites which are the polylactic acid, PLA and rice straw, RS were prepared by using heated two roll-mill at $180^{\circ} \mathrm{C}$. Mechanical properties showed that the tensile strength and elongation at break, $E_{b}$ decreased with 
the increasing of RS while the Young's modulus had increased. The TGA results confirmed that thermal stability of PLA with RS composites decreased when the RS fiber loading increased.

...more

The Addition of Imperata cylindrica as Natural Filler in Epoxidized Natural Rubber Filled Recycled Nitrile Glove: Cure Characteristics and Physical Properties Authors: A.A. Afiratul, N.Z. Noriman, Kamarudin Husin, S.T. Sam, Hanafi Ismail, A.M. Mustafa Al Bakri, Mohd Firdaus Omar, Z. Norhafizah

Abstract: The effects of imperata cylindrica on curing characteristics and physical properties of epoxidized natural rubbers (ENR25) filled recycled nitrile glove (rNBR) were examined. The compounds were prepared by two roll mill at five different compositions of imperata cylindrica $(5,15,25,35$ and $45 \mathrm{phr})$. The size range of imperata cylindrica particles i.e., $0 \mu \mathrm{m}-63 \mu \mathrm{m}$ and $500 \mu \mathrm{m}-700 \mu \mathrm{m}$ were used. The result of cure characterization show that scorch time $\left(t_{2}\right)$ and cure time $\left(t_{90}\right)$ of the ENR25/rNBR decreased with the increased of imperata cylindrica content due to an insufficient amount of accelerator or curing agent and migration of sulphur from filler to the natural rubber. ENR25/rNBR with fine size, $S_{1}$ of imperata cylindrica particles exhibit lower minimum torque $\left(\mathrm{M}_{\llcorner}\right)$compared with the coarse size, $S_{2}$ which resulted in more efficient processing. The maximum torque $\left(\mathrm{M}_{\mathrm{H}}\right)$ of all ENR25/rNBR compounds show the increasing trend with increased imperata cylindrica content due to the good interactions between imperata cylindrica and ENR25/rNBR compounds. For physical properties, ENR25/rNBR compounds with fine size, $\mathrm{S}_{1}$ of imperata cylindrica particles exhibited the higher crosslinking density at all compound ratios meanwhile coarse size, $\mathrm{S}_{2}$ show highest hardness compared to fine size, $\mathrm{S}_{1}$. The results overall indicated that the ENR25/rNBR with fine size, $S_{1}$ of imperata cylindrica particles show better cure characteristics and physical properties (crosslink density and hardness test) compared to coarse size, $\mathrm{S}_{2}$ of imperata cylindrica particles.

...more

\section{Cure Characteristics and Physical Properties} of Imperata cylindrica Activated Carbon Filled SMR L Compounding Authors: M.H. Fatin, N.Z. Noriman, Kamarudin Husin, M.Z. Salihin, N.R. Munirah, Hanafi Ismail, A.M. Mustafa Al Bakri, S.T. Sam

Abstract: The potential of activated carbon as a filler in rubber compound has been reviewed .Cure characteristics and physical properties of Imperata Cylindrica activated carbon filled natural rubber of Standard Malaysian Rubber (SMR L) were studied. SMR $L$ was used as the elastomer and the composition of filler loading were varied from $0-50$ parts per hundred rubber (phr). A semi-efficient vulcanization system was used throughout the study. The cure characteristics of the rubber compound was determined by using rheometer. The samples of hardness and resilience were measured by durometer shore A and Wallace Dunlop Tripsometer. Cure characteristics showed that 
cure time, $t_{90}$ and scorch time, $\mathrm{t}_{2}$ increased as increased filler loading which indicate poor interaction between rubber and filler which slow down the vulcanization time. Minimum torque, $\mathrm{M}_{\llcorner}$and maximum torque, $\mathrm{M}_{\mathrm{H}}$ increased as increased filler loading due to the low processability of the SMR L compounds. Crosslink density and hardness exhibit increment as increased filler loading due to increase rigidity of the SMR $L$ compounds. The resilience will decrease correspondingly as increased in rigidity of the compounds. ...more

\section{Behaviour of Axially Loaded Composite Wall Panel by Using Finite} Element Analysis

Authors: Nur Fitriah Isa, Mohd Zulham Affandi Mohd Zahid, Liyana Ahmad Sofri, Norrazman Zaiha Zainol, Muhammad Azizi Azizan, Muhammad Munsif Ahmad, Mohd Badrul Hisyam Ab Manaf, Mohd Faiz Mohammad Zaki, Mustaqqim Abdul Rahim, Zuhayr Md Ghazaly

Abstract: In order to promote the efficient use of composite materials in civil engineering infrastructure, effort is being directed at the development of design criteria for composite structures. Insofar as design with regard to behavior is concerned, it is well known that a key step is to investigate the influence of geometric differences on the non-linear behavior of the panels. One possible approach is to use the validated numerical model based on the non-linear finite element analysis (FEA). The validation of the composite panel's element using Trim-deck and Span-deck steel sheets under axial load shows that the present results have very good agreement with experimental references. The developed finite element (FE) models are found to reasonably simulate loaddisplacement response, stress condition, giving percentage of differences below than $15 \%$ compared to the experimental values. Trim-deck design provides better axial resistance than Span-deck. More concrete in between due to larger area of contact is the factor that contributes to its resistance. ...more

Effect of Recycled Nitrile Glove (rNBRg) Particle Sizes on Curing Characteristics and Physical Properties of Natural Rubber/Styrene Butadiene Rubber/Recycled Nitrile Glove (NR/SBR/rNBRg) Blends Authors: N.Z. Nik Yahya, Nik Noriman Zulkepli, Hussin Kamarudin, Hanafi Ismail, Sam Sung Ting, Muhammad Ridhwan Jamalul Nasir, Mohd Mustafa Al Bakri Abdullah, Rosniza Hamzah

Abstract: Effects of different particle sizes of recycled nitrile glove (rNBRg) on curing characteristics and physical properties of natural rubber/styrene butadiene rubber/recycled nitrile glove (NR/SBR/rNBRg) blends were studied. The particle sizes of rNBRg were differentiated by the method of producing. $\mathrm{S} 1$ was obtained by cutting the rNBRg (whole glove) into smaller sheet; S2 was obtained by passing rNBRg through 2 rolls mill for 10 times; S3 was obtained by passing rNBRg through 2 rolls mill for 10 times and then mechanically grinded. NR/SBR/rNBRg blends were prepared at 50/30/20 composition using two roll mill at room temperature, with different particle 
sizes, rNBRg (S1), rNBRg (S2) and rNBRg (S3). Scorch time, cure time, minimum torque, maximum torque, crosslink density and hardness of the blends were examined. Results indicated that scorch time, cure time and minimum torque decreased as the rNBRg particle size decreased, while maximum torque and crosslink density increased. The rigidity of NR/SBR/rNBRg blends increased when smaller rNBRg particles were used, which explained the increased in hardness and decreased in resilience of the blends. ...more

The Effects of Trans-Polyoctylene Rubber (TOR) on the Properties of Acrylonitrile Butadiene Rubber/Recycled Natural Latex Gloves (NBR/NRL-G) Compounds Authors: Omar Sabbar Dahham, N.Z. Noriman, Kamarudin Husin, S.T. Sam, M.F. Omar, A.M. Mustafa Al Bakri, H. Rosniza

Abstract: The using of Trans-Polyoctylene Rubber (TOR) as a compatibilizer with acrylonitrile butadiene rubber/recycled natural latex gloves (NBR/NRL-G) has been investigated. The compounds were prepared with different (TOR) loading $(0,2,4,6$ and $8 \mathrm{Phr}$ ) using two roll mills at room temperature. The properties such as cure characteristics, tensile properties, physical properties and morphology were studied. The compatibilized (NBR/NRL-G) compounds exhibited overall good cure characteristics, morphological and physical properties compared uncompatibilized (NBR/NRL-G) compound. The addition of the (TOR) up to 6 Phr was the optimum tensile strength.

...more

Physical and Mechanical Behaviors of SnCu-Based Lead-Free Solder Alloys with an Addition of Aluminium Authors: Nisrin Adli, Nurul Razliana Abdul Razak, Norainiza Saud Abstract: The effect of Al addition on the microstructure, melting point and microhardness of SnCu-Al lead-free solder alloys were investigated with two different compositions of Al which were $1 \mathrm{wt} \%$ and $5 \mathrm{wt} \%$. These solder alloys were fabricated through powder metallurgy (PM) method. The results showed that the melting point and the microhardness value of the $\mathrm{SnCu}-\mathrm{Al}$ lead-free solder alloy were increased as the $\mathrm{Al}$ content increased from $1 \mathrm{wt} \%$ to $5 \mathrm{wt} \%$. The grain growth of SnCu-Al lead-free solder alloy also tends to be retarded due to the homogenous distribution of $\mathrm{Al}$ at the grain boundaries. ...more

The Properties of Linear Low Density Polyethylene/Cyperus Odoratus (LLDPE/CY) Blends: Effect of Sodium Hydroxide Authors: Nik Ahmad Faris Nik Abdullah, Nik Noriman Zulkepli, Sam Sung Ting, Mohd Mustafa Al Bakri Abdullah, Kamarudin Hussin, Rosniza Hamzah 
Abstract: The purpose of this study was to determine the effect of treated Cyperus Odoratus $(\mathrm{CY})$ with sodium hydroxide $(\mathrm{NaOH})$ on the properties of biodegradable plastics made from linear low density polyethylene (LLDPE)/CY blends. Alkali treatments for natural fibers can increased adhesion between the hydrophilic fibers and hydrophobic matric. After $\mathrm{CY}$ was treated with $5 \% \mathrm{NaOH}$ solution, it can be seen that the tensile strength and Young's modulus of the LLDPE/CY blends significantly increased. Therefore, alkali treatments can be considered in modifying the properties of natural fibers.

...more

Compression Characterization of Polyurethane Foams with Different Formulations of Polyol and MDI

Authors: Sinar Arzuria Adnan, Firuz Zainuddin, Hazizan Md. Akil, Sahrim Hj Ahmad

Abstract: Rigid polyurethane (PU) foams were prepared with palm oil based polyols (POP) and methylene diphenyl diisocyanate (MDI) in order to archieve rigid formulations. The effect of the different amount of MDI (1 wt.\%, $1.1 \mathrm{wt} . \%$ and $2 \mathrm{wt} . \%$ ) were studied in density, compressive strength and energy absorption. It was found that the higher compressive strength of the PU foams showed at $1.604 \mathrm{MPa}$ whereas the amount of MDI increased to $1.1 \mathrm{wt}$. \%. The increased amount of MDI to $2 \mathrm{wt} . \%$ showed the higher value in density $\left(0.0531 \mathrm{~kg} / \mathrm{m}^{3}\right)$ and energy absorption with $46.490 \mathrm{~J}$ for $70 \%$ displacement.

...more

Effect of Heat Treatment on Hardness Behavior of AZ91 and AZ91

Reinforced Carbon Nanotube Authors: Nur Hidayah Ahmad Zaidi, Shamsul Baharin Jamaludin, Khairel Rafezi Ahmad, Norzilah Abdul Halif, Sinar Arzuria Adnan

Abstract: In the present work the effect of heat treatment on the hardness behavior of AZ91 and AZ91 reinforced carbon nanotube were investigated under FESEM, Xrd and Rockwell hardness tester. Cnt was embedded homogenously into the matrix due to successfully mechanical alloying using planetary milling. Kinetic precipitation of $\beta$-phase $\left(\mathrm{Mg}_{17} \mathrm{Al}_{12}\right)$ also reveal in the X-ray diffraction pattern. Meanwhile, the artificial aged nanocomposite found decreased in hardness, compare to monolithic has higher value form early aged until 36 hours aging.

...more

Properties of Cement-Based Material Consisting Shredded Rubber as Drainage Material Authors: Muhammad Munsif Ahmad, Fauziah Ahmad, Mastura Azmi, Mohd Zulham Affandi Mohd Zahid, Mohd Badrul Hisyam Ab Manaf, Nur Fitriah Isa, Norrazman Zaiha Zainol, Muhammad Azizi Azizan, Khairunnisa Muhammad, Liyana Ahmad Sofri 
Abstract: Waste tyre caused disposal problem in country all over the world. A lot of research has been done to make use of recycled tyre rubber to minimize waste tyre disposal problem. Recycled tyre rubber has been widely used for civil engineering application such as lightweight concrete and asphalt pavement. However only a few study focused on the development of material using recycled tyre rubber as drainage material for geotechnical purposes. This paper presents the experimental on properties of cement-based material consisting recycled tyre rubber. Specimens were prepared by incorporating different percentage of shredded rubber tyre with mortar. Summation of ten (10) mixes has been investigated to determine the compressive strength, density, porosity and water absorption. From the results, it is concluded that the higher percentage of shredded tyre rubber used, will decreased the compressive strength and increased the porosity and of the material.

...more

Study of Covalent/lonic Cross-Linked Modification on Physical and Mechanical Properties of Chitosan Film as Potential Material in Medical Application Authors: Siti Farhana Hisham, Siti Hajar Kasim, Azreena Mastor, Siti Noorzidah Mohd Sabri, Syazana Abu Bakar, Wedianti Shualdi, Mohd Nasha'ain Nordin, Ahmad Hazri Abdul Rashid, Kartini Noorsal

Abstract: The aim of this study was to investigate the effects of covalent and ionic crosslinked reactions which were respectively done by using genipin and tripolyphosphate (tpp), on the structure and mechanical properties of chitosan film. Both cross-linked and uncross-linked films were prepared by solution casting method and characterized. FTIR spectra showed no characteristic of $-\mathrm{OCH}_{3}$ peak from genipin at $1444 \mathrm{~cm}^{-1}$ which resulted by a new covalent bonding in chitosan film. Reduction in absorption intensity at $1560 \mathrm{~cm}^{-1}$ wave number in chitosan cross-linked tpp films were due to the presence of ionic interaction between the positive charged of amino group in chitosan and negatively charged of phosphate group by tpp. The pattern area from the XRD results showed that the covalent cross-linked had significantly changed on the chitosan's degree of crystallinity. The water contact angle on the surface of covalent/ionic cross-linked chitosan film reached the highest $\theta$ at $82.72^{\circ}$ which indicated more hydrophobic properties was formed. Covalent/ionic cross-linked chitosan also showed the higher mechanical strength with average tensile stress value at $71.25 \mathrm{MPa}$. All finding results demonstrated that cross-linked modification on the chitosan film had successfully reduced the film's hydrophilicity and increased the mechanical properties of the film. ...more

The Effects of Composition on Solid State Sintering of Tungsten-Brass Composites Authors: Baba Gowon, Kahtan S. Mohammed, Shamsul Baharin Jamaludin, Zuhailawati Hussein, Aji D. Aminu, Yusuf A. Lawal, Polycarp Evarastics 
Abstract: In this study, the effect of composition on solid state sintering of tungstenbrass was carried out. The densification of W-Cu has been a difficult problem to the materials engineers. However, the densification behaviour of tungsten-brass in the solid and liquid state is still not known. Tungsten-brass with the composition of $50 \mathrm{~W}$-brass, $60 \mathrm{~W}$-brass, $70 \mathrm{~W}$-brass and $80 \mathrm{~W}$-brass were sintered in a horizontal tube furnace under pure hydrogen environment at the temperature of $900^{\circ} \mathrm{C}$ and the relative sintered density, hardness, electrical conductivity and microstructural characterization was carried out. The relative sintered density and the electrical conductivity increase with the increase in the volume fraction of the matrix (brass) while the hardness decreases with the increase in the volume fraction of brass. The sample with the lowest volume fraction of $\mathrm{W}$ has the highest relative sintered density $(71 \%)$ while the one with the highest volume fraction of $\mathrm{W}$ has the lowest relative sintered density (66\%). The microstructure of the samples was not homogeneous due to mutual immiscibility between W and brass and lack of capillary force to enhance rearrangement and distribution of W and brass. It is obvious from the results that solid state sintering cannot give full densification of tungsten-brass composites.

...more

Effect of Poly(Methyl Methacrylate) (PMMA) on Tensile Properties and Spectroscopy Infrared (FTIR) Characteristics of LDPE/WHF Composites Authors: Soo Jin Tan, A.G. Supri, K.L. Foo, A.M.M. Al Bakri, Y.M. Liew, C.Y. Heah Abstract: In this work, the effect of PMMA in low density polyethylene/water hyacinth fibers composites were prepared and characterized in terms of tensile properties and FTIR characteristics. Water hyacinth fibers (WHF) were incorporated into the LDPE matrix with different fiber loading. LDPE/WHF and LDPE/WHF ${ }_{\text {РMMA }}$ composites were prepared with Z-blade mixer at $180^{\circ} \mathrm{C}$ with rotor speed of $50 \mathrm{rpm}$. The PMMA modified WHF increased the tensile strength and Young's modulus while reduced the elongation

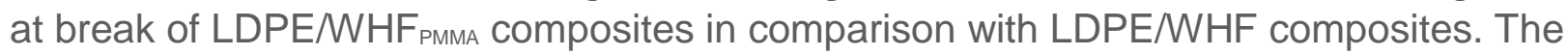
absorption peak at $1736.28 \mathrm{~cm}^{-1}$ indicated the presence of ester carbonyl group $(\mathrm{C}=\mathrm{O})$ in LDPE/WHF ${ }_{\text {PMMA }}$ composites.

...more

Effect of Alkali Treatment Using Calcium Hydroxide and the Fiber Length on the Strength of Sugarcane Bagasse Fibers-Polypropylene Composites

\section{Authors: Juliana Anggono, Suwandi Sugondo, Steven Henrico, Hariyati Purwaningsih}

Abstract: Milling sugarcanes to produce sugar generates by-product called bagasse. Due to the large availability and low cost, the potential of obtaining renewable and biodegradable fibers from bagasse had been explored. To produce fibers from these bagasse, the bagasse was treated in alkali solution using $14 \% \mathrm{v} / \mathrm{v}$ calcium hydroxide, $\mathrm{Ca}(\mathrm{OH})_{2}$ at high temperature $\left(60-70^{\circ} \mathrm{C}\right)$ for 4 hours. After treatment and washed to remove dissolved substances, the fibers were cut into 3 and $5 \mathrm{~cm}$ length. Some fibers 
were prepared in their original length. These fibers were mixed with polypropylene (PP) matrix in weight $\%$ ratios of bagasse fibers/PP 20/80, 25/75, and 30/70 and hotpressed to make composite samples. Composites produced were characterised with tensile test to evaluate their tensile properties. Scanning electron microscopy (SEM) was performed on the fiber surface as well as on the fracture area of the tensile tested samples. Tensile strength of the composite shows an increase with the increase of the fiber length and weight $\%$ ratios of bagasse fibers/PP up to $25 / 75$ and decreases when bagasse fibers were added to $30 \mathrm{wt} . \%$. The highest strength of $11,30 \mathrm{MPa}$ was obtained when $5 \mathrm{~cm}$ fibers were used in a weight $\%$ ratio of bagasse fibers/PP at 25/75. SEM study found a greater number of fibers oriented perpendicular to the tension direction. ...more

Mechanical Properties of Short Fiber and Non-Woven Kenaf Reinforced Polypropylene Composites: Effects of Oil Palm Shell Powder Addition Authors: Mohd Abrar Abd Latif, Mohd Edeerozey Abd Manaf, Loganarrth Maslamany, Muhammad Syafiq Mohd Hussain, Noraiham Mohamad

Abstract: Kenaf is renowned for its renewable and environmental friendly properties. Recently, there is an interest on the application of kenaf-based material for high-end uses such as in the automotive industry. In this study, the effects of oil palm shell powder (OPSP) addition on the mechanical properties of kenaf reinforced polypropylene (PP) composites are investigated. Two types of kenaf are used in this study, i.e., nonwoven and short fiber. For the former, the composites are fabricated by hot pressing a non-woven kenaf sheet sandwiched by thin PP sheets which have been mixed beforehand with OPSP by using internal mixer. For the latter, kenaf short fibers are mixed with OPSP using internal mixer, then compression molded by using hot press. In general, addition of OPSP was effective to improve the mechanical properties of nonwoven kenaf reinforced PP composites, while the kenaf short fiber reinforced PP showed varied results. Composites reinforced with non-woven kenaf showed a larger increase in tensile strength, elongation at break and impact strength with the OPSP addition than those reinforced by kenaf short fibers.

...more

Superhydrophobicity of Textured Ceramic Coating for Corrosion Protection in Marine Applications - A Brief Review Authors: Juyana A. Wahab, M.J. Ghazali, W.M.W. Yusoff, Zainuddin Sajuri, Shaiful Rizam Shamsudin

Abstract: Technology for surface protection in contact with seawater has been studied. It mainly focuses on the capability of superhydrophobicity characteristic. Currently, the application of superhydrophobicity in controlling corrosion problem in the marine environment is still new. The development of superhydrophobicity on the materials surface can be achieved by designing a specific texture pattern in micro-or nanometer scale for producing high roughness surface. This review paper is mainly on the laser 
technology for producing superhydrophobicity characteristic of materials surface. This technique offers the most control and precision over the produced geometry. ...more

Study on the Effect of Porous Silicon Sizes for Potential Visible Photodetector Authors: Alhan Farhanah Abd Rahim, N.M. Sah, I.H. Hamzah, Siti Noraini Sulaiman, Musa Mohamed Zahidi

Abstract: In this work, the characterization of porous silicon (PS) for potential visible light emission was investigated by simulation. SILVACO TCAD simulator was used to simulate PS by using process simulator, ATHENA and device simulator, ATLAS. Different pore diameter sizes of the PS structures were constructed. The structural, optical and electrical characteristics of the structures PS were investigated by currentvoltage (I-V), current gain, spectral response and the energy band gap. It was observed that PS enhances the current gain compare to bulk Si and exhibited photo emission in the visible spectrum which constitutes to the quantum confinement effect of the Si in the PS structures.

...more

X-Ray Diffraction and Dielectric Constant of Lanthanum Doped Barium Titanate Ceramics Authors: Nur Farahin Abdul Hamid, Rozana Aina Maulat Osman, Mohd Sobri Idris Abstract: Undoped barium titanate and lanthanum ( $\mathrm{La})$ doped barium titanate $\left(\mathrm{BaTiO}_{3}\right)$ were studied for ferroelectric properties with the formula of $\mathrm{Ba}_{1-x} \mathrm{La}_{x} \mathrm{Ti}_{1-\times 4} \mathrm{O}_{3}$ for $x=0.1$ and being prepared by using conventional solid state method reaction. The pure phase of this composition which $x=0$ were found at final heating temperatures starting from $1300^{\circ} \mathrm{C}$ and $x=0.1$ at $1350^{\circ} \mathrm{C}$ for overnight in air with intermittent grinding. The changes in the crystal structure of the composition were detected by using X-ray diffraction. Impedance Spectroscopy analysis is carried out to determine the dielectric properties for undoped $\mathrm{BaTiO}_{3}$ and $\mathrm{La}$ doped $\mathrm{BaTiO}_{3}$ for $x=0.1$. ...more

Multi-Layer Microstructure of Sol-Gel Barium Titanate Thin Films for Optical Waveguide Applications Authors: S.H. Najamudin, H.Mohd Yusof, Ala'eddin A. Saif, R.A. Osman, P. Poopalan

Abstract: - Barium titanate $\left(\mathrm{BaTiO}_{3}\right)$ thin films are suitable for many application especially photonics. $\mathrm{BaTiO}_{3}$ thin films are deposited using spin coating with an optimum spin speed of $4500 \mathrm{rpm}$. The samples are then characterized using XRD, AFM and SEM. The results of the XRD analysis showed that both the 5-and 10-coated layers are polycrystalline $\mathrm{BaTiO}_{3}$ with differences in terms of diffraction intensity, due to the number of layers. As for optical application, the surface roughness is the most crucial part. The number of layers of 5 and 10 have thickness of $2.927 \mathrm{~nm}$ and $4.456 \mathrm{~nm}$ RMS. 
...more

High Throughput Graphene Oxide in Modified Hummers Method and Annealing Effect on Different Deposition Method Authors: M.R. Muda, K.N. Hanim, Siti Salwa Mat Isa, Muhammad Mahyiddin Ramli, M.F. Jamlos

Abstract: Graphene sheets offer extraordinary thermal, electronic and mechanical properties which could enhance the performance of the device for various applications. However, a large quantity production and the direct dispersion of graphene or graphite sheets in water without the assistance of dispersing agent has been considered to be a challenging issue. In this study, we reported that by introducing the functional group on the graphene basal plane started from natural graphite can readily form stable graphene oxide (GO) solution in a large quantity through modified hummers method. Structural and physiochemical properties of the GO were investigated with help of Atomic Force Microscopy (AFM), Scanning Electron Microscopy (SEM), Fourier Transform Infrared Spectroscopy (FTIR). The effects of the annealing treatment on a GO surface were analyzed using a Semiconductor Parameter Analyzer (SPA) in order to obtain the electrical resistance measurement. Based on the thermal reduction results, the resistance of drop casting is greater than spray coating which indicates that, the drop casting method is more reliable to be used in any application. ...more

A Study of Fire Retardant Effect in Natural Fiber Composite Panels with Magnesium Hydroxide and Zinc Borate as Additives Authors: Tengku Nuraiti Tengku Izhar, Chan Choon Jiat, Nabilah Aminah Lutpi Abstract: The objective of this study is to investigate the fire retardancy effect of coconut coir, rice husk and sawdust panels which are incorporated with magnesium hydroxide $\left(\mathrm{Mg}(\mathrm{OH})_{2}\right)$ and zinc borate $\left(2 \mathrm{ZnO} \cdot 3 \mathrm{~B}_{2} \mathrm{O}_{3} \cdot 3.5 \mathrm{H}_{2} \mathrm{O}\right)$ as additives. The natural fiber and additives are mixed and cured for one week, with polyester resin and hardening catalyst as binders. Fire retardancy of these panels are tested according to American Society for Testing and Materials (ASTM) Horizontal (D 365) and Vertical Burning (D 3801) tests. Principle of fire retardants and mechanism of polymer combustion are shown in this study too. The study revealed that the sawdust panels with both additives have the highest fire retardancy compared to rice husk and coconut coir panel with both additives.

...more

Rapid Indicators in Detecting Variation of Fly Ash for Making HVFA

\section{Concrete} Authors: Antoni, Rianto Gunawan, Djwantoro Hardjito

Abstract: The use of fly ash as an alternative material for cement substitute in concrete mix already a common practice nowadays. However, as a waste material, fly ash varies in quality and condition, as shown by variation of its fineness, specific gravity, Loss on 
Ignition (LOI) and also on its chemical composition. By measuring the acidity $(\mathrm{pH})$ of the fly ash in water solution, percentage of mass retained on $45 \mu \mathrm{m}$ sieve, and superplasticizer demand of the fly ash, we can develop a quick estimation of the quality of fly ash. This study aims to investigate a quick method to estimate the quality of fly ash by measuring the physical and chemical pointers, as indicator for its properties and the effect on the setting time and compressive strength of mortar. Fly ash content was varied from $0-70 \%$ of the total mass of cementitious materials to make HVFA mortar. Fly ashes were obtained from four power plants in Indonesia. Tests conducted were material characterization, setting time, temperature rise, and compressive strength of mortar at different ages. Different fly ash quality can be shown by the fast pointers; namely $\mathrm{pH}$, superplasticizer demand and \% retained on $45 \mu \mathrm{m}$ sieve. Setting time and strength development were affected by the different properties of fly ash. ...more

\section{A Preliminary Study on Cracking Tendency of Cement Paste Incorporating High Calcium Fly Ash Authors: Verryanto Goenawan, Antoni, Djwantoro Hardjito} Abstract: Fly ash is a waste material from burning coal that can be used to reduce the amount of cement in making concrete and to improve the characteristics of concrete. Besides being able to improve the flowability of fresh concrete, fly ash can also serve to reduce cracking of concrete. But in certain cases, cement paste incorporating fly ash type $\mathrm{C}$ (high calcium fly ash) experiences cracks, right after being released from formwork. The purpose of this study were to investigate the causes of cracking of cement paste incorporating fly ash type $\mathrm{C}$, the influence of fly ash variations, and the countermeasures. The evaluation conducted for this experiment were based on visual inspection and compressive strength test of cement paste at 28 days. Test specimens were made in the form of cement paste with fly ash content of $50 \%$, by mass. Fly ash used was of type $C$ taken from three different batches from one source; with fly ash type $F$ from three different sources used for control specimens. Superplasticizer, silica fume, and calcium carbonate were used as additives to evaluate their effect in mitigating cracks. The results show that the use of fly ash type $\mathrm{C}$ may cause cracks on the surface of hardened paste. Fly ash content, especially $\mathrm{CaO}$ and $\mathrm{MgO}$, are the key factors affecting the cracks tendency on the surface of cement paste, due to expansion. Superplasticizer and silica fume can be used to mitigate cracks of cement paste. ...more

Review on the Effect of Bottom Ash in Performance of Portland Cement Mortar Authors: Ng Hooi Jun, Mohd Mustafa Abdullah Al Bakri, Kamarudin Husin, Soo Jin Tan, Mohd Firdaus Omar

Abstract: Utilization and suitability of bottom ash in Portland cement have been increasing significantly in recent year. Bottom ash has substantial effects on mechanical properties with different composition of replacement in mixture of bottom ash and 
Portland cement. Bottom ash was used to determine the feasibility of the substitution as recycling product from industry depending on the percentage of the bottom ash. On the other hand, bottom ash offers a better solution for maintaining materials characteristic of Portland cement mortar and also provide beneficial mechanical performance. The result of using bottom ash in Portland cement mortar showed that it could make better the mechanical properties and hence disposed bottom ash wastes safely in technical, economic and environmental methods.

...more

Flood Mud as Geopolymer Precursor Materials: Effect of Flood Mud/Alkaline Activator and $\mathrm{Na}_{2} \mathrm{SiO}_{3} / \mathrm{NaOH}$ Ratios on Compressive Strength Authors: Mohd Mustafa Al Bakri Abdullah, Liew Yun Ming, Muhammad Faheem Mohd Tahir, Che Mohd Ruzaidi Ghazali, Kamarudin Hussin, Alida Abdullah Abstract: This paper investigates the potential and suitability of flood mud to be used in geopolymer technique as construction materials. Flood mud was collected from Kelantan, Malaysia and crushed and sieved into powder form. Then, it was mixed with alkaline activator solution (mixture of $\mathrm{NaOH}$ and $\mathrm{Na}_{2} \mathrm{SiO}_{3}$ solutions) followed by curing process to produce flood mud geopolymers. In addition, the effect of varying solids/liquid $(\mathrm{S} / \mathrm{L})$ and $\mathrm{Na}_{2} \mathrm{SiO}_{3} / \mathrm{NaOH}$ ratios on the compressive strength of flood mud geopolymers were also investigated. The result showed that flood mud can be potentially used as precursor materials for geopolymer formation with favorable strength. Optimum compressive strength (24.6 MPa) of geopolymers based on flood mud was obtained at $\mathrm{S} / \mathrm{L}=1.25$ and $\mathrm{Na}_{2} \mathrm{SiO}_{3} / \mathrm{NaOH}=1.0$.

...more

Flood Mud as Geopolymer Precursor Materials: Effect of Curing Regime on Compressive Strength Authors: Mohd Mustafa Abdullah Al Bakri, Mukridz Md Mohtar, Liew Yun Ming, Muhammad Faheem Mohd Tahir, Kamarudin Husin, Januarti Jaya Ekaputri Abstract: This paper studies the effect of curing temperature and curing duration to the flood mud based geopolymer on compressive strength properties. Flood mud was used as a raw material for geopolymer and geopolymer samples were synthesized by using sodium silicate and sodium hydroxide $14 \mathrm{M}$ solution. These samples were cured at different temperature $\left(100^{\circ} \mathrm{C}, 150^{\circ} \mathrm{C}, 200^{\circ} \mathrm{C}\right.$ and $\left.250^{\circ}\right)$ for different curing duration (6h, $12 \mathrm{~h}$ and $24 \mathrm{~h}$ ) respectively. Compressive strength tests were carried out at after 28 days. The compressive strength and SEM analysis of geopolymer products were evaluated. Result showed that the maximum compressive strength was $24 \mathrm{MPa}$ at temperature of $150^{\circ} \mathrm{C}$ for 24 hours. With increasing ageing day, densification of geopolymer gel was observed. ...more 
Thermally Stable Encapsulation Material Based on Green and Red Lanthanide Phosphor for White Light Emitting Diodes Authors: Wedianti Shualdi, Nik Mohd Azmi, Nurul Huda Yusoff, Nor Adhila Muhammad, Khairuldin Mohd Isha

Abstract: This study reported thermal stability of hybrid sol-gel encapsulation materials doped with lanthanides complexes for generating white light. Red and green lanthanide phosphor, Eu (tta) $)_{3}$ phen and Tb (4DBBA) ${ }_{3}$ TPPO were incorporated into VTES:TEOS hybrid sol-gel and dispensed into $360 \mathrm{~nm}$ to $390 \mathrm{~nm}$ UV LED packages. Thermal properties of developed encapsulation material were analysed by TGA. A thermal aging test up to 96 hours was done to check the stability of developed encapsulation material towards UV LED junction temperature of $120^{\circ} \mathrm{C}$ and the luminescence properties changes was observed using photoluminescence measurement. To check the encapsulation material stability on forward voltage, the operation voltage has been increased from $3.0 \mathrm{~V}$ to $4.0 \mathrm{~V}$. The photometric measurement were recorded using integrating sphere for the properties of Colour Rendering Index (CRI), colour temperature and Commission Internationale de L'Eclairge (CIE) colour coordinates. Based on the results, developed encapsulation material produced white colour with CIE colour coordinate of $(0.32,0.35), \mathrm{CRI}$ up to 75 and colour temperature around $6000 \mathrm{~K}$. ...more

\section{Study on Dielectric and Magnetic Properties of MWCNTs/Polyester} Composites Authors: Y.S. Lee, F. Malek, E.M. Cheng, Wei Wen Liu, Kok Yeow You, F.H. Wee, L. Zahid, Mohd Asri Jusoh, A.D.T. Hussain, Gomesh Nair Shasidharan Abstract: This paper is to study the dielectric properties, magnetic properties, and dielectric conductivity of Multi-walled carbon nanotubes (MWCNTs) and polyester (PE) composites. The composites with different amount of MWCNTs (5-15\%) have been studied in the Ku-Band range (12.4-18 GHz). The rectangular waveguide (WR-62) was used to measure the dielectric properties and magnetic properties of the samples. The results show the dielectric properties and conductivity of MWCNTs/PE composites is increasing with the MWCNTs filler increases. The real part of dielectric properties values increase from 5.5 to 26.6 with increasing the MWCNTs loading from $5 \%$ to 15 $\%$. The increasing of MWCNTs filler in the MWCNTs/PE composites does not effects on magnetic properties, the real part and imaginary part of magnetic properties are approximate to 1 and 0 . The highest conductivity of $15 \%$ MWCNTs loading is reach to $11.02(\mathrm{~S} / \mathrm{m})$ at $18 \mathrm{GHz}$. Keywords: composites, dielectric properties, magnetic properties, conductivity ...more

Evaluation of Thermal Properties of the $\mathrm{Fe}_{80} \mathrm{Cr}_{20}$ Nanostructure for Interconnect Application in High Temperature Authors: Abdul Mutalib Leman, Dafit Feriyanto, M.N.M. Salleh, Ishak Baba 
Abstract: Metallic $\mathrm{Fe}_{80} \mathrm{Cr}_{20}$ alloy in thermal stability analysis is investigated. Approached method is combination technique (milled and UT) of ball milling (milled) combined with ultrasonic technique (UT) which is not yet fully explored. From Energy Dispersive x-ray Spectroscopy (EDS) analysis resulted that the composition of $80 \mathrm{wt} \% \mathrm{Fe}$ and $20 \mathrm{wt} \% \mathrm{Cr}$ in individual particle was achieved at milled and UB $4.5 \mathrm{~h}$ sample. Higher thermal stability of treated samples approximately $63 \%$ at $1100{ }^{\circ} \mathrm{C}$ temperature operation which showed by milled and UT at $4.5 \mathrm{~h}$ when compared to raw material. Combination technique shown high prospect to advance exploration in improving thermal stability which suitable for interconnect application.

...more

Electromagnetic Wave Attenuation in Lossy Dielectric Authors: Ade Anis Afrizal, Nurul Khadiko, Fitria Gani Sulistya, Vita Nur Septyani, H. Ahmad Lubis

Abstract: The importance of knowing dielectric value on a medium is to perceive the capability of conducting electromagnetic wave. Most of failure on electromagnetic instruments, were due to an inaccuracy of selecting material. Improper usage of materials may cause the attenuation of electromagnetic energy. So, it is important to measure the attenuation value. In this study, we compared the attenuation value on three media such as clay, silicon and wood. The problem mentioned above, could resolved by applying the electromagnetic propagation formula using skylab program. In this study we compared the effect constitutive parameters to the attenuation value and frequency in three media. The result shows, among three materials, at the same frequency we obtain that electromagnetic energy much easily attenuated on clay compared to other materials followed by silicon and wood. The reason is due to the conductivity value. In this study, we obtain that clay is the most sensitive on attenuation value on frequency followed by silicon and wood.

...more

198

The Effect of Different Remazol Dye Concentrations and Soaking Times in Dye-Sensitized Solar Cell

Authors: Siti Salwa Mat Isa, N. Asyikin M. Anhar, Nur M. Selamat, N. Syahida C. Adib, M.R. Muda, Muhammad Mahyiddin Ramli, N.A.M. Ahmad Hambali

Abstract: Water based Remazol Brilliant Red, Orange and Violet dyes were used as the dye sensitizer in dye-sensitized solar cell. The performance of the solar cell was investigated between the dye concentrations, $0.25 \mathrm{mM}$ and $2.5 \mathrm{mM}$ and three different soaking times which at 3 hours, 12 hours and 24 hours. The adsorption peaks of the dyes were observed using ultraviolet-visible-near infrared (UV-Vis-NIR) Spectrometer and the performance of the dye-sensitized solar cell was measured using Spectrum Parameter Analyzer (SPA). The results show that the device efficiency was increased with dye concentration, but, the DSSC performance at different soaking times performed differently with the previous study. The highest conversion efficiency of 1.125 
\% was obtained for Remazol Brilliant Red at concentration of $2.5 \mathrm{mM}$ at 3 hours soaking time.

...more

Aligned Carbon Nanofibres (CNFs) at the Graphene/Nickel Thin Film Edge

Authors: M.S.H. Shamsuri, Syarifah Norfaezah Sabki, A.H. Norzilah, M.N. Najwa, A.N. Edzatty, H. Alhummiany

Abstract: This work is a preliminary study to investigate the growth of carbon nanofibres (CNFs) on monolayer graphene. The growth of CNFs on graphene has been performed by chemical vapour deposition (CVD) using ferrocene as the catalyst precursor and acetone as the carbon source. Ferrocene in acetone is introduced to the system via spray coating onto the substrate. Graphene film used in this study is grown on nickel (Ni) thin film, which is confirmed to be monolayer. Aligned CNTs are unintentionally obtained, however only at the graphene/Ni thin film edges.

...more

The Effect of Different Reduction Methods on Conductivity of ReducedGraphene Oxide (r-GO)

Authors: Muhammad Mahyiddin Ramli, K.N. Hanim, M.R. Muda, Siti Salwa Mat Isa, M.F. Jamlos

Abstract: Large quantity of graphene oxide (GO) was prepared by Modified Hummer's method, in which graphite was treated with a mixture of sulphuric acid, potassium permanganate and hydrogen peroxide. A chemically reduced graphene oxide ( $r-G O)$ was prepared using sodium borohydride $\left(\mathrm{NaBH}_{4}\right)$, followed by thermal treatment and thermal treatment of chemically reduce using $\mathrm{NaBH}_{4}$. The electrical resistance of $r-\mathrm{GO}$ was measured using Keithley sourcemeter. The results revealed that $\mathrm{r}-\mathrm{GO}$ show lower resistance on thermal reduction which is $2.39 \mathrm{k} \Omega$ compared to chemical reduction and thermal of $\mathrm{NaBH}_{4}$ reduction which is $2.18 \mathrm{M} \Omega$ and $3.16 \mathrm{k} \Omega$ respectively. It can be concluded that thermal reduction is the best method to produce high conductivity $r-G O$ film.

...more

Correlation of Impact Energy from Instrumented Charpy Impact Authors: M.B. Ali, Kamarul Ariffin Zakaria, Shahrum Abdullah, M.R. Alkhari Abstract: This paper proposes the correlation of absorbed energy with calculated energy using the power spectrum density (PSD) method. The total absorbed energy was obtained using the dial/encoder system may significantly vary depending on the strength and ductility of the material. In addition, according to ASTM E23, over $80 \%$ of absorbed energy is inaccurate and approximate. For this reason, we determined the energy collected from the dial/encoder Charpy impact test using the signal processing approach. Strain gauges were connected to the Charpy impact striker and the high frequency data acquisition system in order to capture the dynamic impact strain 
response. Specimens of an aluminium alloy of 6061-T6 and carbon steel 1050 with different velocities and thicknesses were used in the experiment. The specimens are prepared based on the ASTM E23. A collection of signal was converted from the time domain to the frequency domain by means of PSD method and the area under its plot was used to calculate strain energy. The comparison between energy absorbed during the experiment with PSD peak and the strain energy were performed using different materials, velocities and thicknesses. The total energy absorbed for both material with the PSD peak and the strain energy using the dial/encoder system can be linked by a power law equation with $R^{2} 96 \%$ and $R^{2} 94 \%$. Thus, the effects of the strain signal pattern and impact duration with different parameters were correlated with the PSD peak and the strain energy. This correlation using PSD can be used as an alternative for the charpy impact test and solve the problem of inaccurate absorbed energy. ...more

Radiation Enhancement Using Circular Split Ring Meta-Surface Mirror for a Small Patch Resonator

\section{Authors: A.A.M. Ezanuddin, A.H. Ismail, E.I. Azmi}

Abstract: This paper investigate the radiation efficiency enhancement for a small square patch resonator with the integration of single layer circular split ring metasurface mirror (CSRMM) operating at $5.8 \mathrm{GHz}$ using Transmission Line Matrix (TLM) method. The single layer CSRMM provide an appropriate reflection phase to act as a mirror and is able to enhance the resonator gain and efficiency. This work shows a linear phase response from $5.8 \mathrm{GHz}$ to $5.9929 \mathrm{GHz}$ that is sufficient for $50 \Omega$ wireless communication system operation. A siginificant improvement of 0.391 to $0.741 \mathrm{dBi}$ IEEE gain over the whole frequency range was demonstrated. The resonator has an initial radiation efficiency of 0.246 and incremented to 0.406 once CSRMM is inserted. The resonator small size configuration provides adequate space for mounting the mirror close to the resonator, making it more fitting for modern wireless devices. ...more

Keystroke Dynamics for Construction Industry: A Review on Biometric Systems

\section{Authors: Syed Zulkarnain Syed Idrus, Azremi Abdullah Al Hadi, Phak Len Al Eh} Kan, Suhizaz Sudin, Hussin Kamarudin

Abstract: Keystroke dynamics is known to be able to recognise a person associated with their way of typing on a computer keyboard. It is a fea-sible and useful method as an additional component to safety measures for identity verification. Previous studies show how keystroke dynamics can help to improve the recognition systems. Users behaviour when typ-ing, illustrates individual characteristics behind the computer screen. In this paper, we propose to use this application or technology along with a keypad to determine the construction workers' attitude during work-ing hours, whether they have been working within a reasonable time or otherwise. This could possibly be a 
way to monitor their validity period while working. Keywords: Biometrics, keystroke dynamics, pattern recognition, construction.

...more

\section{D Stress Analysis of ITER Tokamak Assembly} Authors: M. Hafiz, M. Afendi

Abstract: International Thermonuclear Experimental Reactor (ITER) is build based on the 'tokamak' concept of magnetic confinement, in which the plasma is contained in a doughnut-shaped vacuum vessel which powered up by the fuel of a mixture of deuterium and tritium. The two isotopes of hydrogen are then heated to a certain temperatures in excess of 150 million ${ }^{\circ} \mathrm{C}$, forming hot plasma. The Blanket Module (BM) is arranged around the plasma to provide thermal and nuclear shielding for the vacuum vessel (VV), magnets, and other external component. Therefore, it is important to determine parameter that would affect the development process of BM. Analysis is very important in the design process for the ITER BM as well as nearby components. So a finite element model was developed on the BM and the detail part of the BM was developed using computer aided design (CAD) software. The detail part was inserted into the VV and several simulations were performed to find out the stress distribution within the wall of the BM. The constraint condition was find out and evaluated. The result shows that the maximum shear stress is $539.97 \mathrm{MPa}$ which exceed the allowable value of $515 \mathrm{MPa}$. The result shows some acceptable stress levels in most of the analysed geometry. The result obtained was used to further modify the BM design in the cases where limits are exceeded.

...more

Circular Split Ring Meta-Surfaces Variation Study as Surface Wave Suppressor Authors: A.A.M. Ezanuddin, A.H. Ismail, E.I. Azmi

Abstract: This work focuses on three different edge variation modified on the same circular split ring (CSR) longest arm of metallo dielectric periodic structure and its corresponding electromagnetic bandgap (EBG) behaviour as an alternative step to suppress surface wave. Three variants of circular split ring were studied to fulfill the requirements: Normal edge, triangular tip and tapered tip. These structures were optimized using Eigenmode Solver (EmS) with Advanced Krylov Subspace (AKS) method for full wave dispersion diagram. Final results shows a stable and good EBG region achieved from this CSR specifically within the 5.9 to $6 \mathrm{GHz}$ region. The normal tip CSR that has a stable and good bandgap exits from $5.9265 \mathrm{GHz}$ to $5.9516 \mathrm{GHz}$ in between mode 5 and 6 . While the triangular tip CSR bandgap is from $6.0214 \mathrm{GHz}$ to 6.0378 GHz and tapered tip is from $6.0214 \mathrm{GHz}$ to $6.0378 \mathrm{GHz}$.

...more

Overview of Artificial Fish Swarm Algorithm and its Applications in Industrial Problems 


\section{Authors: Nurezayana Zainal, Azlan Mohd Zain, Safian Sharif}

Abstract: Artificial fish swarm algorithm (AFSA) is a class of swarm intelligent optimization algorithm stimulated by the various social behaviors of fish in search of food. AFSA can search for global optimum through local optimum value search of each individual fish effectively based on simulating of fish-swarm behaviors such as searching, swarming, following and bulletin. This paper presents an overview of AFSA algorithm by describing the evolution of the algorithm along with all the improvements and its combinations with various algorithms and methods as well as its applications in solving industrial problems.

...more

The Development and Implementation Lean Manufacturing in Indonesian Furniture Industry Authors: Bambang Suhardi, Akiyumas Sahadewo, Pringgo Widyo Laksono Abstract: This research discusses about the principles of lean manufacturing in furniture export industries. The aim of this research is to improve productivity by reducing waste which exists in the production floor. This research discusses about the implementation of Value Stream Mapping (VSM) as waste initial identification instrument, standardization work, and Single Minute Exchange of Die (SMED) as an analysis tool and improvement implementation. Both of that methods are conducted in this research. This research is practically applicable and proven to be able to reduce waste which exists in production floor and to improve the factory's productivity. ...more

Overview of Fuzzy Logic Technique for Modeling Machining Process Authors: Azizah Mohamad, Azlan Mohd Zain, Noordin bin Mohd Yusof Abstract: This paper describes an overview of Fuzzy Logic (FL) application for solving machining problems. The developed fuzzy prediction model is an essential operational guideline for machinist in decision making and adjusting process parameters. This paper also discussed the previous literature that applied the FL in modeling machining process.

...more

\section{Optimization of Surface Roughness in Turning Operation Using Firefly} Algorithm Authors: Nur Farahlina Johari, Azlan Mohd Zain, Noorfa Haszlinna Mustaffa, Amirmudin Udin

Abstract: Recently, Firefly Algorithm (FA) has become an important technique to solve optimization problems. Various FA variants have been developed to suit various applications. In this paper, FA is used to optimize machining parameters such as \% Volume fraction of $\mathrm{SiC}(\mathrm{V})$, cutting speed $(S)$, feed rate $(F)$, depth of cut $(D)$ and machining time $(\mathrm{T})$. The optimal machining cutting parameters estimated by FA that lead to a minimum surface roughness are validated using ANOVA test. 
...more

Green Aircraft Technology Imperatives for Environmental Sustainability Authors: Harijono Djojodihardjo

Abstract: Commercial aviation is experiencing the fast growth exceeding automotive travel; the latter is well known for contributing to air pollution. Commercial aviation impacts climate by two main avenues: the emission of greenhouse gases and cloud effects. While the former impact is similar to other activities that contribute to anthropogenic climate change, the latter is unique to aviation. Anthropogenic solutions that can be offered by Aerospace Technology to address anthropogenic environmental changes, known as green technology initiatives, may only provide partial or temporary solutions. In the efforts to intervene such process and thus maintaining the sustainability of the earth's environment, some scientific and technological guidelines to comprehend the natural phenomena and global changes are reviewed and discussed. Selected efforts devoted to aircraft technology and aviation, for maintaining the sustainability of the earth's environment are elaborated. Particular considerations are given to fuel burn affecting greenhouse gases and cloud effects due to trailing vortices and hence contrail. ...more

\section{Pressure Generated from Head Garment with Padding Insert Used for} Hypertrophic Scar Treatment Authors: A.F. Aiman, M.N. Salleh, K.A. Ismail

Abstract: Pressure garment is a standard non-surgical treatment for hypertrophic scar caused by burn injury. However, the main problem identified was the non-uniform pressure distribution due to the complexity of the contour at the facial area. Therefore, padding was developed to produce more efficient pressure distribution. This study used 3D scanning apparatus to obtain the cross sections of the facial area. The padding was developed using 3D modeling software which act as an insert to fill the gaps at the contact area of the garment and facial areas. The result shows that by inserting the padding underneath the garment, the pressure outputs indicate an acceptable pressure range with the suitable reduction factor for the head garment fabrication. ...more

\section{Buffer Allocation Using 6 Steps Oba Method: A Case Study} Authors: M.S. Ismail, Noorhafiza Muhammad, M.I. Hussain, Zuraidah Mohd Zain, R. Ahmad

Abstract: This paper utilized a simulation software to determine an optimal buffer allocation for any unpaced production line when a set of buffer quantity is known. The optimal buffer allocation will give the highest throughput rate (productivity) to the production line. From the simulation result, a trend of relation between mean processing time $(\mu)$ trend of the stations in the production line and buffer allocation configuration of the buffer slots were studied. It was concluded that for any unpaced production line, the best throughput rate of the production line will be obtained if the buffer allocation 
configuration follow the mean processing time $(\mu)$ trend. By applying this concept, a mathematical relation was formed results in a development of a technique called 6 Steps OBA (optimal buffer allocation) method . In order to validate the result from this 6 Steps OBA method, a case study was carried out in one of the multinational electronics company in Malaysia (Company S). An unpaced and $u$-unbalanced production line was selected and this line was producing a product which is known as model $A$. In this production line, a few possible buffer allocations quantity were allocated on each buffer slots including buffer allocation suggested by 6 Steps OBA method. For each buffer allocation possibilities, the actual production line productivity (throughput rate) was recorded and compared to validate that the best line throughput rate was the buffer allocation suggested by the 6 Steps OBA method. From the overall result, it was proven that the 6 Steps OBA method will give a maximum throughput rate to a production line. ...more

Simulation and Experimental Studies on Optimum Barrel Length for High Impact Penetrator Authors: Ahmad Humaizi Hilmi, Ariffin Ismail, Mohd Firdaus

Abstract: The primary purpose of this project is about simulation and experimental studies for optimum barrel length of a high impact penetrator. This project uses the concept of two-stage light gas gun modified by using shaped charge at the first stage. Sacrificial barrel is the important part for this project. The combination of sacrificial barrel with piston serves to compress the air along the barrel at appropriate pressure. It produces sufficient amount of pressure to rupture the rupture disc and the pressure will force the projectile to travel through the barrel. There is some parameter to be investigated such as volume of air in pump barrel, strength of rupture disc and location of the piston in the sacrificial barrel. Some method is use such as calculation to determine the suitable length for the sacrificial barrel and the thickness of the rupture disc. The parameter will be use to perform simulation that will result in amount of the pressure and velocity of projectile that can be produced. The comparison result from simulation and experimental testing on the condition of sacrificial barrel and piston is obtained in this study. The significance of this project is more on the cost because this project only uses an atmospheric air as a mechanism to launch a projectile. More than that, high impact penetrator can reduce space because it is smaller compare to light gas gun.

...more

Design Specification Determination with Collaborative Approach for Indonesian Short Wheelbase Recumbent Bicycle Authors: Bambang Suhardi, Ilham Priadythama, Cindy W. Fitriyani

Abstract: Determination of specification for product development is useful, as it includes an overview of product-related information. However, it is not an easy thing, especially for new and innovative product. In the view of designer as the subject who has never made the product, he needs to work closely with the manufacturer so that the concept 
can be designed to become a feasible product. In addition, in order to reduce product design life cycle and minimize design errors, the designer needs to communicate and collaborate with the manufacturer. This research proposes a design specification based on the paradigm of Concurrent Engineering (CE) from Collaborative Product Development (CPD) strategy in the development of a new ergonomically designed Short Wheel Base (SWB) Recumbent Bicycle. This collaborative process involved an expert from bicycle practitioner which already had experience in building custom bicycle. The result of this study is a frame set design of the bicycle which considers human anthropometry and the detail list of its components. Beside of that, the process of collaboration with practitioners bicycle produces $37 \%$ change in the components used and 3 changes in shape of design SWB Recumbent Bicycle.

...more

\section{The Satisfaction Preferences Measurement of Profile Design}

\section{Authors: Haeryip Sihombing, Rosidah Jaafar, M.Y. Yuhazri}

Abstract: The purpose of this study is to identify the quality of the product and the key product features based on customer satisfaction through the Kansei Engineering (KE) and Kano Model (KM). There were 509 respondents involved in this survey to answer the questionnaires developed that contains of 8 shampoo bottles design, 6 words representing emotional quality based on Kansei Words (such as Dull Attractive; Difficult to Use $\sim$ Easy to Use; Common Unique; Stiff Elegant; Complicated Simple; Awkward $\sim$ Comfortable), and 6 questions towards functional and dysfunctional attributes of quality based Kano method. Mostly of survey respondents feels that the proposed of shampoo bottle designs as 'Indifferent' (I) quality attributes. Also, the results showed that of the "K2" (in-out mechanism toward liquid inside the shampoo bottle) using 'flip top' cap is mostly having siginificant correlation with the design in the eyes of customers based on 'Stiff Elegant' (SE), 'Difficult Easy' to use (DE) and 'Dull $\sim$ Attractive' (DA). This study found and showed the design of products can be interpreted using Kansei Words towards what the articulation of the design profile that represented the customers' emotional design. ...more

\section{Mathematical Modelling of Surface Roughness on Tropical Wood} Machining Using Response Surface Methodology Authors: Amrifan Saladin Mohruni, M. Yanis, E. Sundari, A.Y. Budiman, E.S. Martomi

Abstract: Surface roughness is an important indicator to assess the surface processing quality and has a decisive impact on the furniture finishing effects. In this research, the application of response surface methodology (RSM) has been carried out for modelling and analysing of influences in the sanding process on wood materials. Surface roughness parameter $R_{a}$ showed surface characteristics of Tembesu, Jati and Petanang. This study is aimed to observe the effect of feed rate and grit size on $R_{a}$. The central composite design (CCD) was used as a design of experiment (DOE). There 
were 8 runs at factorial points and additional 5 replicated runs at the centre point. The sanding process was done using a modified horizontal milling machine. The results are statistically analysed by using Design Expert software. It was found that increasing of feed rate had a positive effect on the roughness value of $R_{a}$ and greater feed rates increased the surface roughness. On the other hand, grit size influenced negative effect. Larger grit size affected the smoother surface roughness. At the end of this study, it was also revealed that the optimum machining conditions in terms of feed rate and grit size were $17 \mathrm{~mm} / \mathrm{min}$ and 240 for Tembesu and Jati, while Petanang was 18.63 $\mathrm{mm} / \mathrm{min}$ and 226.52 .

...more

\section{Designing a Low Cost Endoskeletal below Knee Prostheses with the Implementation of Appropriate Technology Authors: Lobes Herdiman, Nyoman Adiputra, Ketut Tirtayasa, I.B. Adnyana Manuaba}

Abstract: The endoskeletal below knee prostheses was commercially available in Indonesia. More advanced products also available in the market but they come with expensive price and high maintenance cost. This paper presents a design concept of an affordable endoskeletal below knee prostheses for daily living with functional ankle joint. The design was developed through the application of appropriate technology approach from the total ergonomics framework which consists of 7 characteristics; technically feasible, ergonomic, energy saving, economical, socioculturally acceptable, environmental friendly, and trendy. The result is an endoskeletal below knee prostheses with multiaxis joint system and energy store-return components installed on its modular ankle joint.

...more

Mismatch Analysis of Elementary School Desk and Chair Using Monte Carlo Simulation Authors: Cucuk Nur Rosyidi, Susy Susmartini, Singgih Ady Pratama, Lu'lu' Purwaningrum, Satoshi Muraki

Abstract: In this paper, we analyze the mismatch between the desk and chair key characteristics and pupil's anthropometric data. Samples were taken from public elementary schools in six regions (Surakarta, Sukoharjo, Sragen, Karanganyar, Boyolali, and Klaten) of Central Java Indonesia. Mismatch comparisons are made among existing desk and chair, Indonesia National Standard (SNI) dimensions, and the dimensions from pupil's anthropometric data. Monte Carlo simulation method is used to find the smallest mismatch among the anthropometric percentiles data. From the analysis of simulation result using Crystal Ball software, seat width and under desk clearance have the lowest mismatch. The seat height and desk height from desk and chair dimensions from pupil's anthropometric data have the lowest mismatch comparing to the existing and SNI desk and chair dimensions.

...more 
A Study of Tool Motion in 2 Dimensional Ultrasonic Assisted MicroMilling

Authors: Mohd Rasidi Ibrahim, Noor Hakim Rafai, Erween Abd. Rahim, Kai Cheng, Hui Ding

Abstract: This paper present a study of the 2 dimensional ultrasonic vibration assisted micro-milling (UVAM) focused on the tool motion shape and tool trajectory. The cutting characteristics in 2 dimensional are in view by considering the trajectory of the amplitude of vibration towards tool locus into the workpiece during the tool rotation are explore in depth. The vibration platform travel in $X_{f}$ direction known as a feedrate movement, thus the $X$ and $Y$ axis vibration generate simultaneously through the workpiece surfaces. Amplitude value acting on $\mathrm{X}$ and $\mathrm{Y}$ axis proposed a major effect as it will effectively change the shape of tool trajectory between oval and eclipse. This investigation found the major advantages of UVAM is come from the alternating cycle's gap phenomena between tool and workpiece. The reduction of prediction of cutting force and the thinning chip thickness formations has been observe during the investigation. The theoretical finding will be discussing the potential to extended tool life, surface roughness and material removal rate in the conclusion for future research plan. ...more

\section{Mega Floats: Floating Offshore Remote Terminal (FORT) towards} Sustainability Life Cycle Assessment Authors: Asmawi Abdul Malik, Mohd Zamani Ahmad, Azura Ahmad Radzi, Ahmad Faizal Ahmad Fuad, Nur Hanani Ahmad Azlan

Abstract: The life cycle model of Mega Float: Floating offshore fishing terminal (FORT) for deep sea fishing industry is presented in this paper. FORT is a totally new concept of a mega float for deep sea fishing application. It is aimed at increasing productivity through reducing travelling time to fishing ground by providing critical support services such as loading and unloading and minor maintenance and repair of boat and equipment at sea close to the fishing ground. The immediate concern is surely on its life cycle cost and techno-economic viability. The system is huge and remotely located far offshore and hence the element of sustainability and environmental friendliness and safety are some of the major investment issues. Immediate cost consideration includes the relatively high initial/acquisition cost and operation and maintenance costs and the intention is to at least self-sufficient by generation income from the services offered. Therefore, hybrid algorithm of cash flow and life cost cycle is applied in FORT implementation. The new derivation of the mathematical model for FORT application is developed to life cycle assessment principle [1-3]. The algorithm requires data that could be best produced based on forecast demand and projected cost. For ease of use the lengthy algorithm will be presented in a computer-based package. ...more 
Digital All-Pass Filter Modeling Based on Desired Group Delay Using Advanced Material: A Review on the Signal Processing Part Authors: Faizah Abu Bakar, Sohiful Anuar Zainol Murad, Rizalafande Che Ismail, Muzamir Isa

Abstract: This paper presents a review on three types of techniques in designing digital all-pass filters based on group delay. All the three methods use the same basic concept rooting back to the requirement of a stable transfer function of the filter which should be a minimum-phase type, and the denominator group delay. The most optimized of the three is chosen to be implemented in MATLAB in order to decrease the group delay variation of a $5^{\text {th }}$ order Chebyshev low-pass filter with cut-off frequency of $160 \mathrm{MHz}$. The digital transfer function of the low-pass filter is obtained from the analog transfer function by means of bilinear transformation. The sampling frequency of the digital LPF is 100 times the cut-off ffrequency to retain the response of the analog LPF. Both of the filters are then cascaded together and the overall group delays variations are analyzed. The variations of group delay shows a reduction but the price paid is the increase of the overall group delay of the system.

...more

338

Fiber Length Optimization of Ring Cavity Multi-Wavelength Brillouin Fiber Laser Utilizing Fiber Bragg Grating Authors: A. Zakiah Malek, N.A.M. Ahmad Hambali, M.H.A. Wahid, M.A.M. Azidin, Siti Salwa Mat Isa, M.M. Shahimin

Abstract: In this paper, we experimentally investigated the performance of ring cavity multi-wavelength Brillouin fiber laser utilizing fiber Bragg grating which operated in the C-band wavelength region. The combination of stimulated Brillouin scattering and selective wavelengths gave a new invention in the optical fiber communication. Five different lengths of single mode fiber are used in order to get the best gain medium for stimulated Brillouin scattering effect. Up to 33 of Brillouin Stokes signals and 31 of antiStokes signals were obtained when $10 \mathrm{~km}$ fiber length was used in the laser system. The average value optical signal to noise ratio of $15 \mathrm{~dB}$ has been achieved. The broadening bandwidth of Brillouin Stokes signals also occurred at the center wavelength of $1550 \mathrm{~nm}$ based on the $3 \mathrm{~dB}$ bandwidth of $5 \mathrm{~nm}$ fiber Bragg grating.

...more

Comparative Characteristics between L-Band EDFA, L-Band EDFA Utilising Single FBG and Dual Stage L-Band EDFA Utilising Dual FBG Configurations Authors: M. Safuan Zainudin, N.A.M. Ahmad Hambali, Goh Chee Seong, M. Shakirin Abu Hurera, N. Roshidah, M.H.A. Wahid, M.M. Shahimin, A. Zakiah Malek Abstract: The development was conducted with three configurations of L-Band EDFA, L-Band EDFA utilising Single FBG and Dual Stage L-Band EDFA utilising Dual FBG. The configurations utilising the FBG using 35 meter M-12 Fibercore EDF as the gain medium to amplify the input signal power in the L-band region. The gain enhancement 
has shown by the Dual Stage L-Band EDFA utilising Dual FBG by injecting low input signal power of $-10 \mathrm{dBm}$. The flat amplitude of OSNR at $33.358 \mathrm{~dB}$ was produced at injected wavelength from $1570 \mathrm{~nm}$ to $1605 \mathrm{~nm}$.

...more

All-Optical XOR Logic Gates: Insights and Comparisons Authors: Mohd Azarulsani Md Azidin, M.H.A. Wahid, N.A.M. Ahmad Hambali, M.M. Shahimin, A. Zakiah Malek

Abstract: Three XOR photonics logic gate configurations namely semiconductor optical amplifier-Mach Zender interferometer cross phase modulation (SOA-MZI XPM), SOAMZI cross gain modulation (XGM) and terahertz optical asymmetrical demultiplexer (TOAD) XOR are analysed and compared in terms of generated power, optical signalto-noise ratio (OSNR) values and bit error rate (BER) signal quality. The highest generated power is possessed by the TOAD at $23.5 \mathrm{dBm}$, the SOA-MZI XPM showed the most extinction ratio or OSNR with $109.6 \mathrm{~dB}$ whereas the best $\mathrm{BER}$ is recorded in the SOA-MZI XGM at $4.42 \times 10^{-22}$.

...more

Energy Saving Switched-Mode Regulator in Motorcycle Power Supply Authors: Mohd Fikri Che Husin, Faizah Abu Bakar, A.F. Hasan, Rizalafande Che Ismail, Tg Muhd Aiman Tg Mohd Yusof, Mohd Norhafiz Hashim, Muhd. Firdaus Mohd Radzi

Abstract: A new approach to designing Switched-Mode Power Supply (SMPS) for motorcycle power supply is presented. It uses an alternative way to efficiently regulate power output from a stator generator instead of using conventional Power Rectifier Regulator (PRR). Energy saving switch mode regulator shown the fuel consumption were less used compared using conventional PRR from several experiments using an alpha prototype of SMPS.

...more

\section{Design and Analysis on Symmetric MEMS Inductor}

\section{Authors: N. Khalid, N.I.M. Nor, W.M.W. Norhaimi, Zaliman Sauli, Vithyacharan} Retnasamy

Abstract: This paper presents the design and analysis of new proposed topology microelectro-mechanical system (MEMS) inductor. This new symmetric MEMS inductor is designed to reduce the total length of the conductor strip and hence reduce the resistance of the metal tracks. This results significant increases in the quality $(\mathrm{Q})$ factor of the inductor. In this paper, the MEMS inductor is designed using CoventorWare ${ }^{\circledR}$, which is powerful software for MEMS computer aided design (CAD), modeling and simulation. Results indicate that new symmetric inductor topology has thehighest Qfactor and it hasbeenimproved bytwo times compared to circular inductor. The analysis revealed that area of the symmetric inductor has reduced by $37.5 \%$ compared to the 
circular inductor. Result has proved that the reduction of length of the conductor strip has reduced the resistance of the metal tracks and results in a high Q-factor inductor. ...more

Extrinsic and Intrinsic Modeling of InGaAs/lnAIAs pHEMT for Wireless Applications Authors: Norhawati Ahmad, S.S. Jamuar, Muammar Mohamad Isa, Siti Salwa Mat Isa, Muhammad Mahyiddin Ramli, N. Khalid, N.I.M. Nor, Shahrir Rizal Kasjoo, Sohiful Anuar Zainol Murad, M. Missous

Abstract: This paper presents the linear modelling of high breakdown InP pseudomorphic High Electron Mobility Transistors (pHEMT) that have been developed and fabricated at the University of Manchester (UoM) for low noise applications mainly for the Square Kilometre Array (SKA) project. The ultra-low leakage properties of a novel InGaAs/InAIAs/InP pHEMTs structure were used to fabricate a series of transistor with total gate width ranging from $0.2 \mathrm{~mm}$ to $1.2 \mathrm{~mm}$. The measured DC and SParameters data from the fabricated devices were then used for the transistors' modelling. The transistors demonstrated to operate up to frequencies of $25 \mathrm{GHz}$. These transistors models are used in the design of Low Noise Amplifiers (LNAs) using fully Monolithic Microwave Integrated Circuit (MMIC) technology. ...more

Defect Segmentation of Semiconductor Wafer Image Using k-Means Clustering Authors: N.H. Saad, N. Mohamad Sabri, A.F. Hasan, Azuwa Ali, Hariyanti Mohd Saleh

Abstract: Nowadays, quality control becomes an important issue in semiconductor manufacturing industry. The rate of production with respect to time gives a lot of issues in the industry. In most semiconductor assemblies, a lot of defects generated from various processes in semiconductor wafer manufacturing need to be inspected manually using human experts and this process required full concentration of the operators. This human inspection procedure, however, is time consuming and highly subjective. In order to overcome this problem, implementation of machine vision will be the best solution. This paper presents defect segmentation of semiconductor wafer image based on colour features with k-Means clustering algorithm which can be adopted in machine vision system. In this work, the segmentation process is carried out in two stages. The first stage comprised of clustering the pixels in the image based on their colour and spatial features. Then the clustered pixels are merged to a specific number of regions. The proposed approach is being evaluated using defected wafer image. The experimental results show that it can be used to segment the defect correctly. By using this method, it is possible to increase the computational efficiency since it will avoid feature extraction for every pixel in the image. ...more 


\section{Optimization of L-Band Ring Cavity Brillouin Erbium Fiber Laser}

Authors: N. Roshidah Yusof, N.A.M. Ahmad Hambali, R. Othman, W. Mokhzani, M.H.A. Wahid

Abstract: In this paper, the performance of ring cavity Brillouin Erbium fiber laser (BEFL) within L-band wavelength region are discussed. Introducing Erbium doped fiber as a secondary gain medium into conventional Brillouin fiber laser configuration is the best alternative to maximize the Brillouin Stokes power (output power) and to sustain the gain flatness. Few parameters comprising length of fiber, pump power and tunable laser source power are varied to obtain the optimum output power. From the simulation process, a maximum Brillouin Stokes power of $54.75 \mathrm{dBm}$ is produced as $16 \mathrm{dBm}$ Brillouin pump power and $1480 \mathrm{~nm}$ pump laser are injected to the configuration. ...more

The Development of Novel High Speed - Low Noise pHEMT Device for Lossless Underwater Optical Communication Authors: Muammar Mohamad Isa, Siok Lan Ong, Chanuri Charin, Norhawati Ahmad, Siti Salwa Mat Isa, Muhammad Mahyiddin Ramli, N. Khalid, N.I.M. Nor, Shahrir Rizal Kasjoo, M. Missous

Abstract: We report the development of two epilayers namely the baseline highly strained channel and enhanced low gate leakage samples. The Hall data shows that the enhanced epilayer portraying higher sheet carrier concentration, but comparable carrier mobility in the 2-DEG layer, as compared to the baseline sample. The WinGreen simulation also conformed the enhanced epilayer advantages where wider Schottky barrier is observed and subsequently double carrier concentration is simulated in the channel. Both samples show low AuGe/Au Ohmic contact resistivity of approximately $0.16 \Omega . \mathrm{mm}$. A tremendous advantage on $1 \mu \mathrm{m}$ Schottky gate leakage is also recorded on enhanced epilayer where the leakage is more than seven times lower than that of the baseline sample. The resulted characteristics are much better than the reported submicron device, thus this device has find an important application in high-gain lossless transmission, especially in underwater optical communication system. ...more

\section{High Speed All-Photonic Flip-Flop Operation at a Single Wavelength} Authors: U. K. Sahbudin, M.H.A. Wahid, M.A.M. Azidin, N.A.M. Ahmad Hambali, N.R. Yusof, M.M. Shahimin

Abstract: This work is based on dual Mach-Zehnder interferometer with semiconductor optical amplifiers in both arms. The proposed flip-flop operates at a single wavelength. A bidirectional coupler is placed at the end of the system to observe the output at set and reset terminals. The signals modulate the injected photon rate in the SOAs thus forming photonic flip-flop function. The photon injection rate is modulated due to selfgain modulation and self-phase modulation that occur in the SOAs towards demonstrating optical bistability. Switching between states of the flip-flop occur at full width half maximum of $32 \mathrm{ps}$. The output power of this flip-flop is around $24.5 \mathrm{~mW}$. It is 
observed that the switching energy can be adjusted to a low level by decreasing the injected currents into the SOAs. The injection and the input power are the two parameters that govern the whole operation of the designed flip-flop.

...more

Nondestructive Fruit Ripeness Detection System and its Spectral

Analyses

Authors: N.H. Hasanuddin, M.H.A. Wahid, M.A.M. Azidin, N.A.M. Ahmad Hambali, N.R. Yusof, M.M. Shahimin

Abstract: This work focuses on the nondestructive fruit ripeness detection system at difference maturity stages. The study involved a two-step approach which is the absorption and reflection spectral analysis. In this system, light dependent resistor (LDR) is used as the light sensor and displayed on the LCD screen of its resistivity. Portable spectrometer is adopted for measuring the reflection and absorption before processed by simple electronic Arduino-based circuit. The results of the photonic ripeness detection system show that the ripe fruit has higher light reflection rate in comparison to the unripe fruit. If the average value of the resistance is in between 400 600 the fruit is classified as still in immature period. Where as the resistance of $610-800$ indicates the fruit is matured. The growth of fruit determines the difference ripeness levels and its resistivity too.

...more

Room Access Control System Using Facial Image Recognition Authors: Resmana Lim, Frans Rotinsuluand, Petrus Santoso

Abstract: The aim of the project is to implement a facial recognition system for access control to enter a room. The facial image captured by a webcam and then be detected/tracked using Haar face tracking algorithm. Principal Component Analysis (PCA) and Linear Discriminant Analysis (LDA) algorithm have been used for face recognition. The system was tested with 10 users from the member of a laboratory room. Each user registered 100 images for training of the PCA and LDA. The recognition rate achieved using PCA was $70 \%$ and $97 \%$ for LDA. ...more

\section{Leak Detection in Gas Pipeline Using Hilbert-Huang Transform} Authors: Nurul Fatiehah Adnan, Mohd Fairusham Ghazali, Makeen M. Amin, A.M.A. Hamat

Abstract: This paper proposes a leak detection method using acoustic. The Hamming chirp signal injected into the pipeline system and the estimation of the leak location from the delay time passing by the reflection in the pipeline if there is a leak. By using HilbertHuang Transform (HHT), it can give a useful signal to verify the leak. HHT transforms Empirical Mode Decomposition (EMD) and Hilbert Spectrum analysis to perform timefrequency analysis. The leak location can be detected by multiplying by the speed of sound. This simple method gives accurate leak location and easy to implement. 
...more

Real-Time Self-Tuning Speed Controller: Performance Comparison between Engine Fuelled with Palm Methyl Esters and Petroleum Diesel Authors: M.N. Azuwir, Mohd Sazli Saad, Mohd Zakimi Zakaria Abstract: This paper investigates the performance of a real-time self-tuning speed controller designed to track and regulate at various engine speeds. The controller was tested with an automotive engine fuelled with petroleum diesel and and palm oil biodiesel (Palm Methyl Esters) within speed range of $1800 \mathrm{rpm}$ to $2400 \mathrm{rpm}$. A selftuning control algorithm based on pole assignment method together with on-line model parameters estimation strategy based on the recursive least squares method are adopted. The ability of the controller to track, regulate at various engine speed and also to reject disturbances applied for both type of fuel are compared and presented. The results confirmed that the controller performed very satisfactorily. ...more

Overview of Harmony Search (HS) Algorithm for Green Manufacturing Industries Authors: Ashanira Mat Deris, Azlan Mohd Zain, Roselina Salehuddin, Safian Sharif

Abstract: The successful optimization process of machining parameters is significantly important to the green manufacturing industries. However, the optimization process of machining problem is difficult to solve using conventional optimization techniques. Hence, the computational approach methodology such as Harmony Search (HS) is considered as an alternative way for optimization process in manufacturing industries. This paper discusses the overview of Harmony Search (HS) to optimize the machining parameters in machining process. Example of previous works that applied HS algorithm in machining optimization problems are also discussed. ...more

Gravitational Search Algorithm for Engineering: A Review Authors: Anis Farhan Kamaruzaman, Azlan Mohd Zain, Suhaila Mohamed Yusuf, Noordin Mohd Yusof

Abstract: This paper presents a review on gravitational search algorithm (GSA).

Nowadays, GSA has been used in various engineering studies such as production cost, production time, power consumption and emission. The GSA also mainly focuses to solve the problem related to optimization, modeling, scheduling and clustering. This paper also highlights the current researches using improved GSA.

...more

$$
\text { ...more }
$$

Appraisal of Mega Float - Floating Offshore Remote Terminal (FORT) on Catenary Mooring for Deep Water 


\section{Authors: Asmawi Abdul Malik, Mohd Zamani Ahmad, Azura Ahmad Radzi, Ahmad Faizal Ahmad Fuad, Nur Hanani Ahmad Azlan}

Abstract: With the development of offshore fishing and deep sea exploitation intensifies, floating offshore remote terminal (FORT) which having many advantages can better adapt to the complicated environment of deep sea in numerous offshore platform. Due to the hull likely to to resonance phenomenon, FORT has more intense motion compared to other hull form types. Therefore, the main challenge of FORT in the deep sea operation is to design effective mooring system. This paper introduced the dynamic response by utilizing the computational effort associated with time-domain simulation of single anchor leg mooring (SALM). The influenced or the effect of significant wave height (SWH) over the structure is discussed. It is shown that a comparison of different SWH value in terms of their stability properties is sufficient and adequate; relative merit is assessed through comparison of full systems that have been designed to minimum cost, and to common performance specifications. It is found that single point or catenary systems, can outperform both static and dynamic solutions at the preliminary stage. Moreover, the results indicated that the position ability and mooring strength of SALM system whose intermediate material is studless chain of catenary mooring system on the premise that satisfies API specification at the same time. ...more

\section{Effectiveness of Safety Management in Oil and Gas Project} Authors: Idris Othman, M. Napiah, M.F. Nuruddin, M.M.A. Klufallah

Abstract: The industry of oil and gas will be always constantly adapting to changes over time, whether in terms of technology, market demands or price thus increase the operational risk and danger in the operation. The purpose of this research is to study on the current practices of safety management implemented in the upstream part in the industry and its effectiveness, altogether to emphasize on the importance of safety management system in the industry. This research focus on the implemented safety management in upstream sector of oil and gas industry especially in PETRONAS Carigali Sdn. Bhd in Malaysia and evaluate and investigate its effectiveness.

Questionnaire survey is conducted regarding safety and the data and results gained from the survey are analysed using the Relative Importance Index (RII) and also by using Average Index (Al). The research put safety management as the main factor in preventing and reducing accidents and incidents to occur in industries of the oil and gas and emphasize on awareness and importance of managing safety in oil and gas industry.

...more

Effectiveness of Human Resource Utilization in Oil and Gas Project Authors: Idris Othman, M. Napiah, M.F. Nuruddin, M.M.A. Klufallah

Abstract: Employees are very important to every organization. This study attempts to examine the effectiveness of current human resource management utilization and practices in oil and gas projects in Malaysia, as well as to study the importance of 
having effective human resource management practices utilization. The human resource management practices namely training and development, performance appraisal, compensation, employee empowerment and ownership as well as work environment are the main practices that has being focused. A questionnaire form has been distributed to the employees of PETRONAS Carigali SDN BHD (PCSB), a leading oil and gas operator in Malaysia including their contractors.

...more

\section{Dynamic System Models Sutami Hydropower Plant Indonesia to Calculate the Economic and Environmental Aspects of Hydropower Plant Operation}

Authors: Daniel Rohi, M. Bisri, Seoemarno, A. Lomi

Abstract: The development of the power sector is required to consider not only the environmental factors but also the economic and security factors. Management of electrical energy in Indonesia faced a major problem because of the shortage of energy production demand continues to increase $7.1 \%$ annually and the energy production is also very depending on fossil energy sources which dominate $85 \%$ of the total power generation. This condition will lead to increasing gas emissions in greenhouse by 78.01 million tons per year. Evaluation of existing plants with a dynamic model of the system will be a consideration for the sustainability of hydropower operation. The simulation results of the Sutami HEPP show more economical and more eco-friendly than fossil energy-based power plant. It is important to build and maintain a HEPP in Indonesia today, due to the potential based on these considerations, the capacity and the reduction of greenhouse gas emissions.

...more

Energy and Environment Implications of Long-Term Power Development Involving Renewable Energy: A Case of Timor Island, Indonesia Authors: Yusak Tanoto, Daniel Rohi

Abstract: This paper presents a long-term electricity energy supply-demand model of Timor Island, Indonesia. Implications of projected demand growth within the observed area towards the available supply as well as the amount of $\mathrm{CO}_{2}$ emission is taken into account. As its main objective is to review and to present initial comparison of the longterm electricity planning prepared by the utility, the analysis is carried out using the bottom-up energy system model. Unlike the common electricity long-term demand projection that is usually constructed based on the factors related to the electricity growth, the model is developed based on the simple projection considering historical electricity demand users. According to the analysis, the planned power plants would not able to meet the elecricity demand in the case of high growth demand scenario. The variation of $\mathrm{CO}_{2}$ emission that is obtained from the considered scenarios is also shown. ...more 


\title{
Effect of Alkali Treatment Using Calcium Hydroxide and the Fiber Length on the Strength Of Sugarcane Bagasse Fibers-Polypropylene Composites
}

\author{
Juliana Anggono, ${ }^{1, a)}$ Suwandi Sugondo, ${ }^{1, b)}$ Steven Henrico, ${ }^{1, c)}$ \\ and Hariyati Purwaningsih ${ }^{2, d)}$, \\ 1) Department of Mechanical Engineering - Petra Christian University, Surabaya 60236, Indonesia \\ 2) Department of Materials and Metallurgical Engineering, Institut Tekonologi Sepuluh Nopember, \\ Surabaya 60111, Indonesia \\ a)julianaa@petra.ac.id, b) aeusug@indo.net.id, ${ }^{c)}$ huangsemin@gmail.com, \\ d) hariyati@mat-eng.its.ac.id
}

Keywords: alkali treatment, calcium hydroxide, sugarcane bagasse fibers, polypropylene

\begin{abstract}
Milling sugarcanes to produce sugar generates by-product called bagasse. Due to the large availability and low cost, the potential of obtaining renewable and biodegradable fibers from bagasse had been explored. To produce fibers from these bagasse, the bagasse was treated in alkali solution using $14 \% \mathrm{v} / \mathrm{v}$ calcium hydroxide, $\mathrm{Ca}(\mathrm{OH})_{2}$ at high temperature $\left(60-70^{\circ} \mathrm{C}\right)$ for 4 hours. After treatment and washed to remove dissolved substances, the fibers were cut into 3 and $5 \mathrm{~cm}$ length. Some fibers were prepared in their original length. These fibers were mixed with polypropylene (PP) matrix in weight \% ratios of bagasse fibers/PP 20/80, 25/75, and 30/70 and hotpressed to make composite samples. Composites produced were characterised with tensile test to evaluate their tensile properties. Scanning electron microscopy (SEM) was performed on the fiber surface as well as on the fracture area of the tensile tested samples. Tensile strength of the composite shows an increase with the increase of the fiber length and weight $\%$ ratios of bagasse fibers/PP up to 25/75 and decreases when bagasse fibers were added to $30 \mathrm{wt} \%$. The highest strength of $11,30 \mathrm{MPa}$ was obtained when $5 \mathrm{~cm}$ fibers were used in a weight \% ratio of bagasse fibers/PP at $25 / 75$. SEM study found a greater number of fibers oriented perpendicular to the tension direction.
\end{abstract}

\section{Introduction}

In recent years there have been a strong motivation in the world society which favors in natural materials to replace non-degradable synthetic materials due to the growth of awareness of global environmental aspects as well as sustainable living. Maximising the use of natural resources, reducing consumption, and recycling are some of the possible approaches to meet that future demands.

Agricultural production inevitably produces by-products (residues) such as leaves and straws that currently become waste and have little use in applications. Sugarcane is one of the main agricultural products in Indonesia after palm oil, coconut, and rubber with its area of plantations in 2012 according to Central Statistics Bureau (Biro Pusat Statistik) covered 198.8 thousand ha. ${ }^{[1]}$ In the sugar mills, bagasse is usually used as fuel for boilers. However, due to its low caloric content, its burning process is inefficient and even cause environmental problems due to the resulting smoke. At the other hand, there are other problems raised concerning storage area for the bagasse and the environment associated with its disposal. Understanding that bagasse is also fibrous residue like other natural fibers, i.e. coir, pineapple fiber, flax fiber and kenaf fiber which they have been used as reinforcing fibers for the manufacturing green composites using polymer matrix, therefore many researchers have performed studies on bagasse fibers as potential reinforcing fibers. Preliminary research has been carried out by studying the effect of variations in the ratio of \% weight bagasse/ PP of 20/80; 25/75; and 30/70 on the tensile strength of the composite. ${ }^{[2]}$ The alkali treatment was applied to reduce the hydrophylicity of fibers which resulted in high moisture absorption and weak adhesion to matrix materials. Bagasse was treated using sodium hydroxide and treated-sugarcane bagasse gave the best reinforcement for composites after 2 hours of treatment due 
to the excellent fiber-resin bonding. Pereira et al. applied treatment using sulfuric acid solution on sugarcane bagasse followed with bleaching using acetic acid and sodium chloride. ${ }^{[3]}$ They reported that after bleaching, the fibers were found rich in cellulose content. This work attempts to study the performances of bagasse fibers/PP composites which the bagasse fibers were treated using calcium hydroxide. Calcium hydroxide was chosen because that alkali solution is less hazardous compared to $\mathrm{NaOH}$. Various length of treated bagasse fibers were prepared including the fibers in their original length. Composite samples were made using various length of fibers then tensile test and SEM study were performed to investigate their strength performance in relation with the microstructure of the fracture cross sectional area. Fourier transform infrared spectroscopy (FTIR) was used to understand the effect of calcium hydroxide treatment given to the bagasse fibers on the fiber surface modification.

\section{Research Methods}

Materials Preparation. The raw materials used to produce the composite samples were polypropylene (PP) and sugar cane. They were both available in the fibers form (Fig. 1). PP fibers were obtained from a local carpet industries, PT. Classic Prima Carpet Industries. PP fibers were cut into $1 \mathrm{~cm}$ long to ensure a homogenous mixture with bagasse fibres during mixing. Initially, bagasse fibers were neutralised by soaking the fibers in $70 \%$ ethanol for 1 hour. This step was done before alkali treatment. Neutralization aimed to prevent the bagasse from degradation due to bacterial fermentation reaction that produced volatile material with an unpleasant smell and acidifying the media used. ${ }^{[4]}$ After drying in the oven at $200^{\circ} \mathrm{C}$ for $30 \mathrm{~s}$, alkali treatment was applied to the bagasse which aimed to remove the layer of lignin and hemicellulose on the fibers surface so that creates good adhesion between the fiber and the matrix. Bagasse was soaked in $14 \% \mathrm{v} / \mathrm{v}$ $\mathrm{Ca}(\mathrm{OH})_{2}$ heated at $60-70^{\circ} \mathrm{C}$ for 4 hours. Completing the alkali treatment, bagasse fibers were rinsed with distilled water for several times. To ensure they were clean from the alkali solution, a $\mathrm{pH}$ check on the rinsed water was implemented. The fibers were dried in the oven at $200^{\circ} \mathrm{C}$ for $30 \mathrm{~s}$. Dried fibers were then cut into $3 \mathrm{~cm}$ and $5 \mathrm{~cm}$ length. Some were left in their original length.

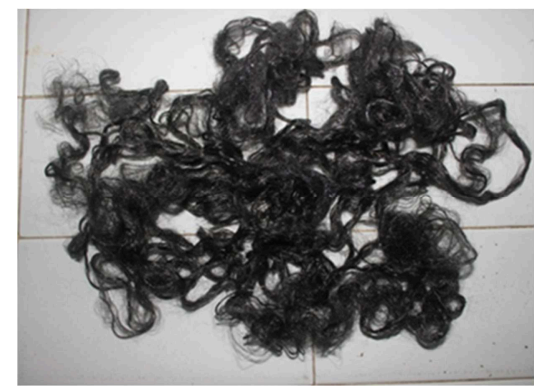

a)

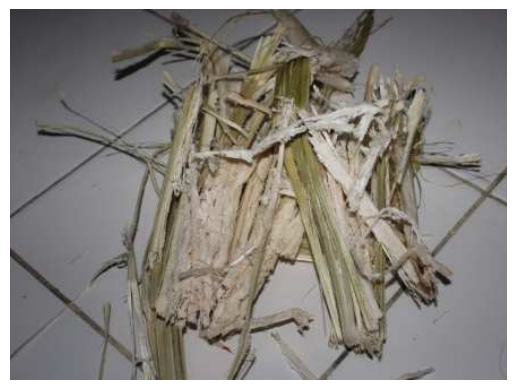

b)

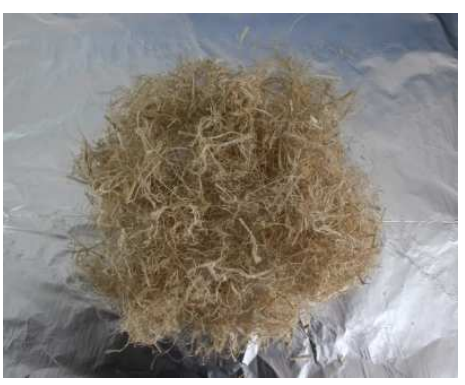

c)

Figure 1 Materials used to make composite samples a) PP, b) as-received bagass fibres, and c) treated bagasse fibers

The next step after alkali treatment was mixing the bagasse fibers and PP. A weight total of $60 \mathrm{~g}$ consisting of bagasse fibers and PP was placed in a mixer using centrifugal blower. They were mixed for 3 minutes. The mixture was then placed in a hotpress machine which was set at a heating temperature of $175^{\circ} \mathrm{C}$ and pressure of $9,8 \mathrm{kPa}$ with a duration of 3 minutes. Curing was performed at room temperature. A $38 \times 15 \mathrm{~cm}^{2}$ hotpressed composite was produced and then tensile test specimens were prepared according to ASTM D 638M-03. Tensile test was performed using Instron DX model with maximum capacity of 60 tonnes. After all samples were tensile tested, microstructural study using SEM (Scanning Electron Microscopy FEI type Inspect S50) was performed with the observation focused on the fracture cross section of the tensile test specimens. Characterisation on the fibers in isolation was also done using SEM and FTIR (Thermo Scientific Nicolet model) to study the effect of calcium hydroxide treatment on the surface morphology and chemical structure. 


\section{Results And Discussion}

Thickness of Composite. Composite thickness was measured from samples used for the tensile test. Thickness was measured using micrometer Links Brand with an accuracy of $0,01 \mathrm{~mm}$. Fig. 2 shows the relationship of composite thickness with fibers length and \% wt. ratio of bagasse fibres/PP. The increase in ratio or in number of bagasse fibres added to PP increases the thickness of the composites. That phenomenon was understood that the bagasse fibers which were stiffer than PP formed like a 'preform' in the mixture. As their amount was increased, they filled in the mould of the hotpress machine and stacked in thicker layer. PP melted during the hotpressing and filled in the spaces among bagasse fibers. Composites which used $3 \mathrm{~cm}$ treated fibers have the lowest thickness in all \% wt. ratio of bagasse fibres/PP in the range of 2,45-2,78 mm. Fibers with $5 \mathrm{~cm}$ length give a composite thickness in a range of 2,48-3,28 $\mathrm{mm}$. As with fibers of original length, the composite thickness is the highest compared to composites using $3 \mathrm{~cm}$ and $5 \mathrm{~cm}$ fibers, i.e. thickness is $2,56 \mathrm{~mm}$ and $3,49 \mathrm{~mm}$ in the ratio of $20 / 80$ and $30 / 70$ respectively. Fibers from original length group were taken for sampling and their length was measured. The length data obtained were from 3 to $24 \mathrm{~cm}$ and the majority of fibers were with a length of $12-21 \mathrm{~cm}(70 \%)$. This length distribution of bagasse fibers could vary from sample to sample and might give slightly different thickness of the composite produced.

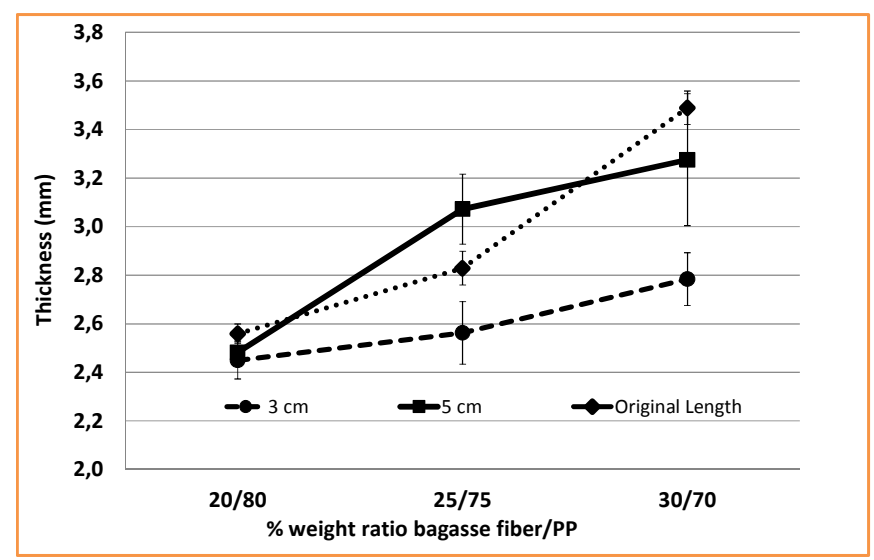

Figure 2 Composite thickness against bagasse fiber length and wt. \% ratio of bagasse fiber/PP

Tensile Properties. Composites using untreated fibers were made to study their tensile properties and compared with composites made from treated fibers so that the effect of alkali treatment using $\mathrm{Ca}(\mathrm{OH})_{2}$ can be evaluated. As other previous findings, alkali treated fibers contributed to a higher composite strength compared to raw or untreated fibers. ${ }^{[5]}$ An increase of $35 \%$ in strength was indicated when 25 wt. \% of treated fibres were used in the composites (Fig.3a). A decrease of strength was observed when $30 \mathrm{wt}$. \% fibers used both treated and untreated as insufficient PP was available to wet the fibers surface.

Fig. $3 \mathrm{~b}$ shows the tensile strength of the composites made with different length of treated bagasse fibers in various wt. \% ratio of bagasse fiber/PP. The shortest bagasse fibers used, i.e. $3 \mathrm{~cm}$ contributed the lowest strength of the composite produced. The reported strength was 4,84 MPa and 5,54 $\mathrm{MPa}$ in wt. \% ratio of bagasse fiber/PP of 20/80 and 25/75 respectively. The increase of strength to $8,22 \mathrm{MPa}$ when the bagasse fibers added to PP was $30 \mathrm{wt} \%$ needed a further study as the result was quite different from the composites using different fiber length. The trend shown from tensile test results in Fig. 3 is an increase in strength when bagasse fibers added up to wt. \% ratio of bagasse fiber/PP 25/75 and the strength decreases when the ratio is increased to 30/70. Increasing wt. \% ratio of bagasse fiber/PP from 20/80 to $25 / 75$ resulted in a strength increase of $33 \%$ from $8,51 \mathrm{MPa}$ to $11,30 \mathrm{MPa}$ in composites using $5 \mathrm{~cm}$ fibers. As with composites employing fibers with original length, there was not found a significant increase in strength with the ratio. The strength continued to drop when the bagasse fibers were added to $30 \mathrm{wt} . \% .{ }^{[2]}$ The drop in strength was $35 \%$ and $20 \%$ in composites using $5 \mathrm{~cm}$ and original length of fibers respectively. This finding was related to the availability of PP in the mixture which was not sufficient to wet the bagasse 
fibers resulting in poor interfacial fiber-matrix adhesion therefore it decreases the strength of the composites at fiber content of $30 \mathrm{wt} . \%$.

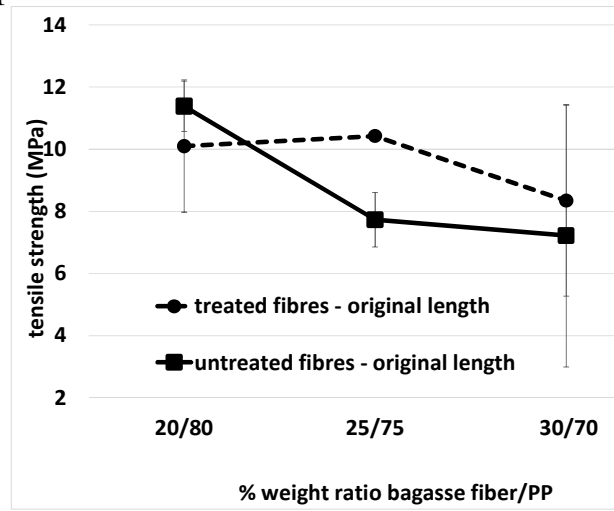

a)

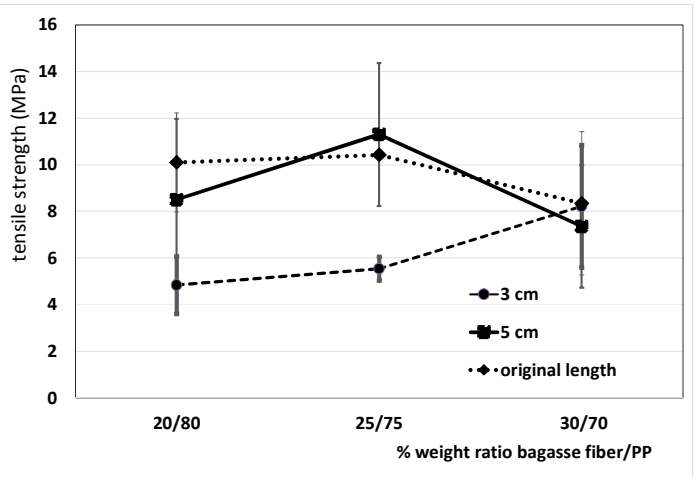

b)

Figure 3 Tensile strength of composite samples a) using original length of fibers - comparing treated and untreated fibers and $b$ ) different fiber length and \% wt. ratio of bagasse fiber/PP

Structural Characterization. Bagasse fibers in isolation were examined using FTIR and SEM. Fig. 4a shows the FTIR spectra from untreated and 4-hour treated fibers.

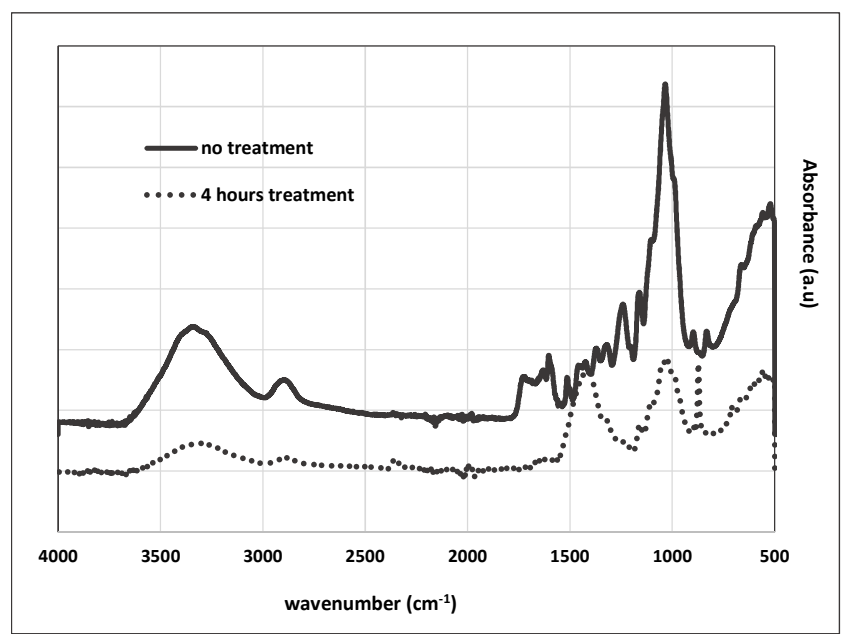

a)

Figure 4 a) FTIR Spectra of untreated and treated bagasse fibers b) and c) SEM micrographs of untreated fibers and treated fibers respectively.
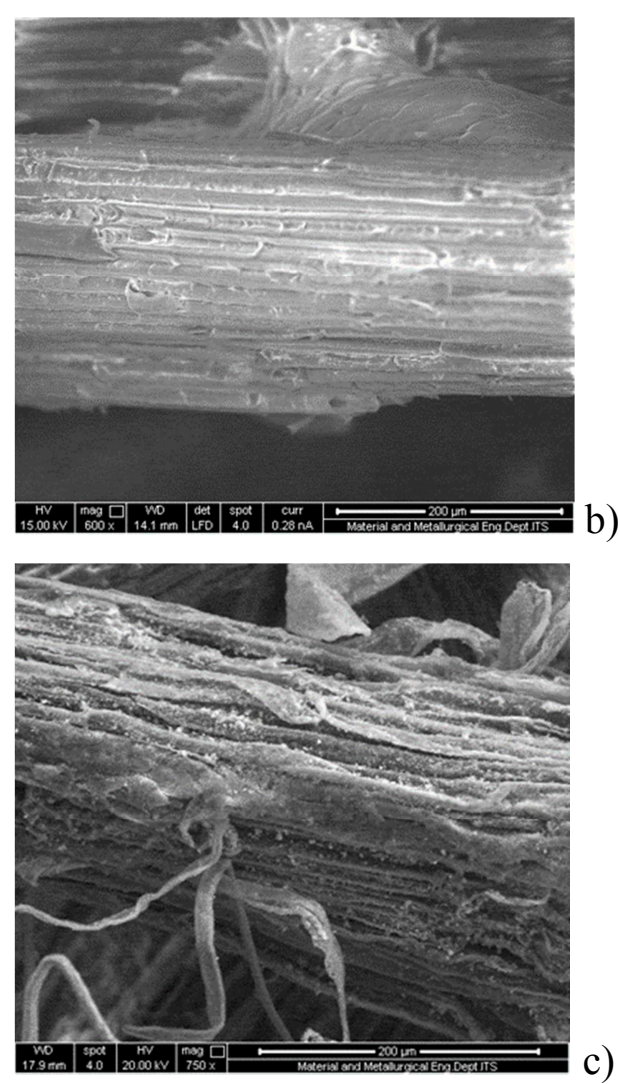

c)

The components of bagasse include cellulose $43.8 \%$, hemicellulose $28.6 \%$, lignin $23.5 \%$, ash $1.3 \%$, and other components $2.8 \%{ }^{[6]}$ They can vary depending on the climate, soil condition, and the crop age of plant. The $\mathrm{CH}$ stretch at $2894 \mathrm{~cm}^{-1}$ is present in both untreated and treated fibers. The obvious differences between the untreated bagasse fibers and treated fibers were noted in the range from $2000-700 \mathrm{~cm}^{-1}$. The peak $1730 \mathrm{~cm}^{-1}$ indicates the $\mathrm{C}=\mathrm{O}$ stretching of the acetyl groups of hemicellulose ${ }^{[7,8]}$ and only shown in untreated fibers. The disappearance of that peak indicates the removal of hemicellulose from the fiber surfaces after treatment. There is an indication of carbonate peaks in the range of $1500-1400$ and $872 \mathrm{~cm}^{-1}$. The spectra $1250 \mathrm{~cm}^{-1}$ which is a lignin spectrum was no longer found in sugar cane fibers that have been given alkali treatment. SEM study was performed to confirm the influence of alkali treatment on fiber surface. SEM micrograph on 
Fig. $4 \mathrm{~b}$ shows surface of untreated fiber. Fig. $4 \mathrm{c}$ shows morphological changes as a consequence of lignin and hemicellulose removal from the surface. The micrograph shows fibrilation of cellulose bundle with bright small particles deposited on the surface of treated fibers. Those particles were identified by EDX analysis having calcium. These particles can be related with identification of $\mathrm{CaCO}_{3}$ in the FTIR spectra.

Fig. 5 shows microstructure at the fracture surface of composite sample using $5 \mathrm{~cm}$ fibers with 20/80 wt.\% ratio of bagasse fibers/PP demonstrating fibers clustering in the composites (Fig.5a). Another observation in Fig. $5 \mathrm{~b}$ reveals the clustering of fibers and lack of PP matrix. It was observed the orientation of some fibers in the composites was in transversal direction (Fig. 5b). All those microstructural data explained the small increase in strength obtained in the composites using treated fibers.

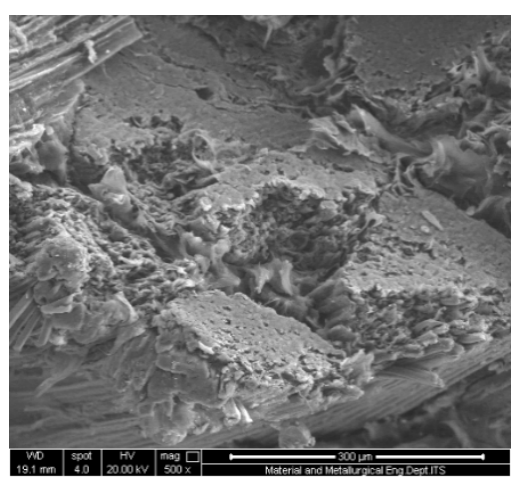

a)

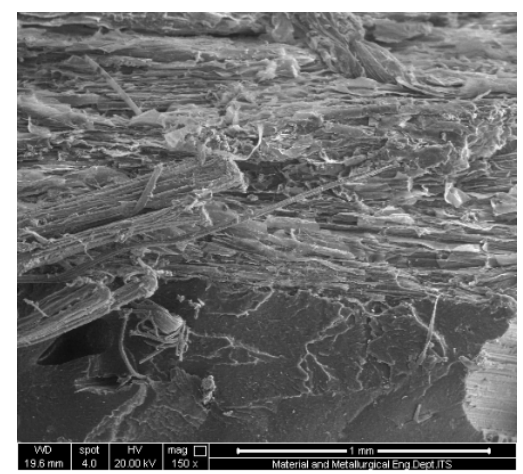

b)

Figure 5 SEM micrographs on fracture surface of composite sample using $5 \mathrm{~cm}$ fibers with 20/80 wt.\% ratio of bagasse fibers/PP. The micrographs show a) fibers clustering and b) orientation of fibers in transversal direction.

\section{Conclusions}

Alkali treatment using $14 \% \mathrm{v} / \mathrm{v} \mathrm{Ca}(\mathrm{OH})_{2}$ bagasse fibers in solution has removed lignin and hemicellulose as shown with FTIR and SEM study. Composite thickness increases with fiber length as well as with weight ratio of bagasse/PP. The strength of the composites was affected by the fiber length and alkali treatment. The highest tensile strength $(11,30 \mathrm{MPa})$ was obtained in composites with bagasse/PP weight ratio of $25 / 75$ and fiber length $5 \mathrm{~cm}$.

\section{Acknowledgements}

We thank Mr. Martinus Salombek and Ms. Russava Istiani for their assistance with materials characterization.

\section{References}

[1]. Information on http://www.bps.go.id /menutab.php?tabel=1\&kat=3\& id_subyek $=54$.

[2]. J. Anggono, N. R. Habibi, S.Sugondo, in: Alkali Treatment On Sugarcane Bagasse To Improve Properties Of Green Composites Of Sugarcane Bagasse Fibers-Polypropylene, edited by Dileep Singh and Jonathan Salem, Volume 35, Issue 2 of Ceramic Engineering and Science Proceedings, Mechanical Properties and Performance of Engineering Ceramics and Composites IX, p. 139, John Wiley (2014).

[3]. P.H.F. Pereira, et al.: Bioresources 6 (3) (2011), p. 2471-2482.

[4]. J.L. Leite et al.: Brazilian Journal of Chemical Engineering, 21(2) (2004), p. 253-260.

[5] D. Verma, et al.: J. Mater. Environ. Sci., 3 (6) (2012), p. 1079-1092.

[6] S. M. Luz, A.R. Gonçalves, and A.P. Del'Arco, Jr: Composites Part A: Applied Science and Manufacturing 38(6) (2007), p. 1455-1461.

[7] J. Biagiotti, et al. : Polym Composite, 25(5) (2004), p.470-9.

[8] W. Liu, et al.: J. Mater. Sci., 39 (2004), p. 1051-4. 